The Krebs Cycle Connection: Reciprocal Influence Between Alternative Splicing Programs and
Cell Metabolism

\author{
Giuseppe Biamonti ${ }^{*}$, Lucia Maita and Alessandra Montecucco* \\ Istituto di Genetica Molecolare, Consiglio Nazionale delle Ricerche, Pavia, Italy
}

Alternative splicing is a pervasive mechanism that molds the transcriptome to meet cell and organism needs. However, how this layer of gene expression regulation is coordinated with other aspects of the cell metabolism is still largely undefined. Glucose is the main energy and carbon source of the cell. Not surprisingly, its metabolism is finely tuned to satisfy growth requirements and in response to nutrient availability. A number of studies have begun to unveil the connections between glucose metabolism and splicing programs. Alternative splicing modulates the ratio between M1 and M2 isoforms of pyruvate kinase in this way determining the choice between aerobic glycolysis and complete glucose oxidation in the Krebs cycle. Reciprocally, intermediates in the Krebs cycle may impact splicing programs at different levels by modulating the activity of 2-oxoglutarate-dependent oxidases. In this review we discuss the molecular mechanisms that coordinate alternative splicing programs with glucose metabolism, two aspects with profound implications in human diseases.

Keywords: splicing regulation, histone modifications, piruvate kinase, 2-oxoglutarate-dependent dioxidases (2-OGDD), lysine demethylases (KDM), m6A demethylase, DNA demethylases (TETs)

Cells tune their metabolic state in response to extracellular signaling and nutrient availability (1). Thus, quiescent and differentiated cells metabolize glucose through glycolysis followed by oxidative phosphorylation in mitochondria with the production of $\sim 30$ molecules of ATP for each glucose molecule $(2,3)$. In contrast, rapidly proliferating normal and tumor cells use energetically inefficient "aerobic glycolysis" (4) (with the production of only 2 ATP molecules) in which pyruvate, i.e. the final product of glycolysis, instead of being imported into mitochondria to fuel the Krebs cycle (also known as the tricarboxylic acid -TCA-cycle) is reduced to lactate and secreted in the extracellular milieu (see Figure 1). The choice between these two metabolic pathways is tightly controlled mainly by the expression and activity of pyruvate kinase M (PKM) isoforms that are altered in tumors. Although energetically inefficient, this metabolic reprogramming, known as Warburg effect, is beneficial to cancer cells since glycolysis intermediates can be used in biosynthetic anabolic pathways.

Alternative splicing of gene transcripts is a potent and versatile mechanism to modulate gene expression in response to a wide range of physiological and pathological cues and stressing events. Deciphering the mechanisms that control splicing decisions and connect alternative splicing programs to the whole set of cell functions remains a main subject of investigation with profound implications for human disease. A common feature of cancer cells is the unbalanced expression of splicing variants $(5,6)$. This profound deregulation of splicing programs is rarely due to mutations in the affected genes or in genes for splicing factors (7). Notable exception are myelodysplastic syndromes (MDS) (8), a heterogeneous group of disorders that affect hematopoietic progenitor 


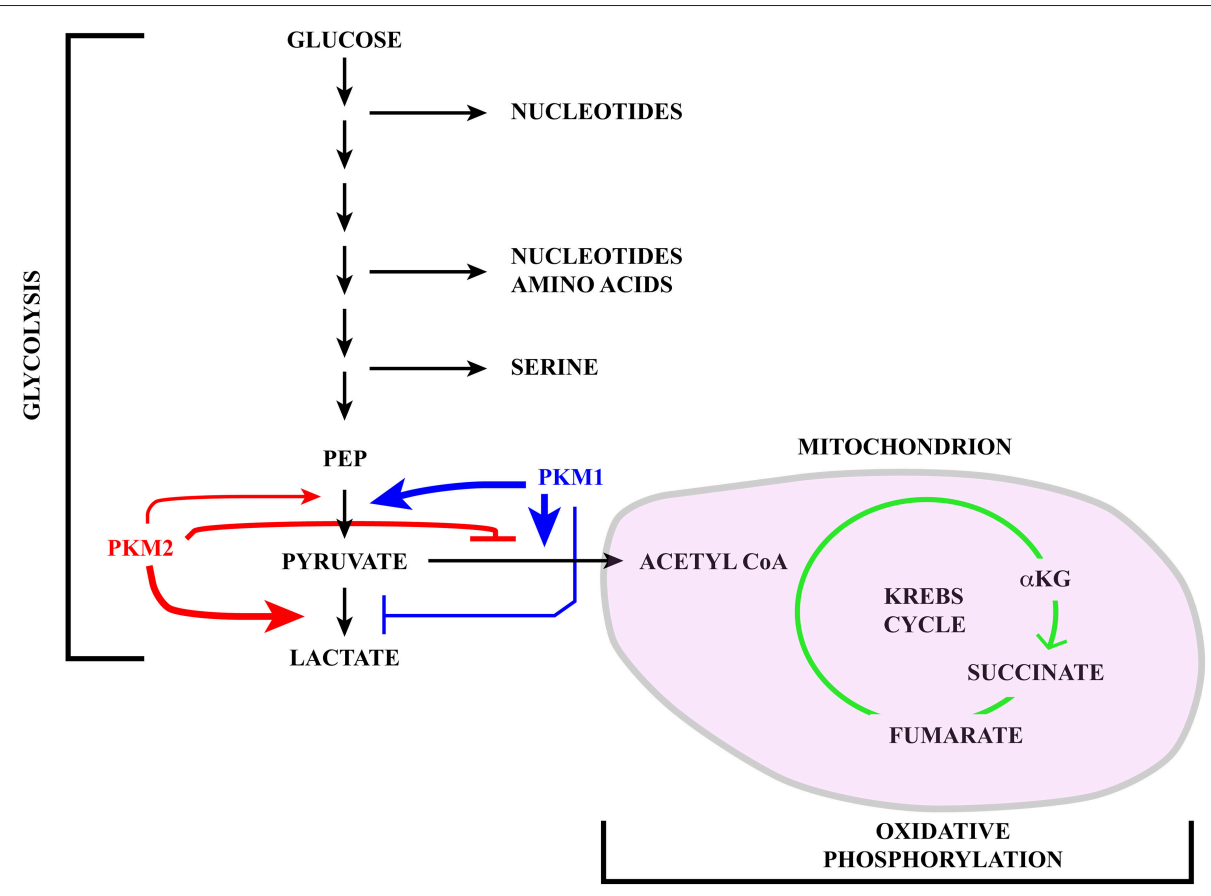

FIGURE 1 | Schematic representation of the glucose catabolism highlighting glycolysis and oxidative phosphorylation in the mitochondrion (pink). Pyruvate kinase (PK) catalyzes a rate limiting step of glycolysis in which a phosphate group is transferred from phosphoenolpyruvate (PEP) to ADP, leading to the production of one molecule of ATP and pyruvate. PKM1 (blue) and PKM2 (red) are generated via alternative splicing of PKM transcripts. While PKM1 is constitutively active, the activity of $\mathrm{PKM} 2$ is regulated in response to a number of signaling pathways. Active PKM2 tetramers promote pyruvate oxidation to acetyl-CoA, in this way fueling the Krebs cycle, whereas PKM2 dimers less efficiently catalyze the last step of glycolysis, inhibit pyruvate oxidation and induce reduction of pyruvate to lactate.

cells and the production of different types of blood cells, and chronic lymphocytic leukemia (9). More than $50 \%$ of MDS cases are caused by somatic heterozygous mutations in spliceosomal proteins SF3B1, SRSF2, U2AF35, U2AF65, and the U2AF-related gene ZRSR2 [for a review see (10)]. More frequently splicing deregulation originates from alterations in signaling pathways that target the expression or activity of splicing regulators $(6,11-13)$. Interestingly, a number of studies have recently begun to unveil the impact of cell metabolism on splicing decisions $(6,12,14-18)$. Key players in this regulatory program are members of the 2-oxoglutaratedependent dioxygenase (2-OGDD) superfamily that act as sensors of metabolic alterations and energetic stress.

In the first part of this review we briefly introduce the mechanisms underlying splicing decisions. A particular emphasis is given to the pivotal role played by chromatin organization in splice site selection, since this layer of regulation is highly sensitive to the metabolic status of the cell. Thereafter, we focus on the reciprocal influence of alternative splicing and glucose metabolism. In particular we discuss:

1) How alternative splicing of pyruvate kinase $M(P K M)$ gene transcripts can impact glucose catabolism by directing the choice between glycolysis and full oxidation of glucose through the Krebs cycle;

2) The role of 2-oxoglutarate-dependent dioxygenases (2OGDD) in controlling alternative splicing. Intermediates of the Krebs cycle influence cell features relevant to oncogenic transformation and their levels are altered by specific gene mutations $(19,20)$ or in response to changes in growth conditions. These oncometabolites act by modulating the activity of 2-OGDDs that specifically target DNA, RNA, and proteins.

The connection between 2-OGDDs activities and splicing programs is frequently mediated by the epigenetic landscape, which in turn is modulated in response to metabolic changes (21) by two classes of enzymes: writers and erasers. Writers include DNA methyltransferases (DNMTs), histone acetyltransferases (HATs), and histone methyltransferases (HMTs). Recently, it has been shown that epigenetic programs act also through the reversible $\mathrm{N}^{6}$-adenosine methylation $\left(\mathrm{m}^{6} \mathrm{~A}\right)$ of RNA molecules by the METTL3/METTL14 complex (22). Erasers include histone deacetylases (HDACs), DNA demethylases, histone demethylases (HDMs), and $\mathrm{m}^{6} \mathrm{~A}$ demethylases ALKBH5 and FTO.

Although the activity of most of these enzymes can be modulated in response to metabolic changes (21-23), the strongest influence of metabolism on epigenetic organization involves "erasers" of methylation patterns that belong to the large 2-OGDDs superfamily.

\section{SPLICING REGULATION AND CHROMATIN}

Splicing consists of the precise removal of intronic sequences from the primary gene transcript (pre-mRNA) to produce a 
mature mRNA molecule. This reaction is carried out by the spliceosome, a complex molecular machine assembled in a stepwise manner on the pre-mRNA and composed of five small nuclear ribonucleoparticles (U1, U2, U4, U5, and U6 snRNPs) and a large number of proteins (24). The spliceosome recognizes short elements with a loose consensus sequence at exon-intron boundaries ( $5^{\prime}$ and $3^{\prime}$ splice sites $-5^{\prime}$ ss and $3^{\prime}$ ss) and at the branch point, which makes the selection of splice sites particularly challenging. Even more so if one considers that internal exons in human cells have an average size of $132 \mathrm{nt}$ and are frequently flanked by introns of thousands of nucleotides in length (25). These features, on the other hand, offer the opportunity of alternative splicing (AS) events that increase transcriptome and proteome complexity (26). The vast majority ( $>90 \%$ ) of human genes produce transcripts that undergo alternative splicing (27). AS profiles are regulated during development and cell differentiation, in a tissue specific manner and in response to physiological stimuli and different types of cell stress (28).

In addition to splice site sequences, several elements contribute to splicing decisions $(29,30)$. A key role is played by splicing regulatory elements (SREs), located both in exons and introns, that can promote (enhancers) or inhibit (silencers) the selection of a particular splice site (31) (see Figure 2A). SREs act by recruiting specific RNA binding proteins (RBPs). The splicing outcome, in fact, is determined by the set of RBPs bound to the pre-mRNA in ribonucleoprotein (RNP) complexes. The protein moiety of these complexes is dictated by the RNA binding specificity, concentration and post-translational modification pattern of each RBP. Two main groups of ubiquitously expressed RBPs with a role in splicing regulation have been characterized in detail: hnRNP (heterogenous nuclear ribonucleoproteins) proteins and splicing factors of the SR (Ser-Arg rich) family. However, the number of splicing regulators, some of which are expressed in a tissue-specific manner, is continuously expanding (32-34).

Splicing can follow two alternative strategies: intron or exon definition (see Figure 2B). According to the intron definition model, the assembly of the spliceosome is guided by intronic sequence elements. This strategy operates during the removal of short introns, which are the rule in lower eukaryotes (30). The excision of long introns in mammalian genes $(25,29)$, instead, relies on the exon definition mode of splicing, in which the exon boundaries are recognized and selected with the help of additional protein-RNA interactions established across the exon. As extensively discussed in several excellent reviews (29, 30, 35), splice site selection is influenced by two further elements: (1) the rate of transcription and (2) chromatin organization. This reflects the fact that splicing is mainly co-transcriptional (36). Studies in yeast have recently proven that the splicing reaction is usually completed as soon as the intron emerges from RNA polymerase II (RNAPII), when less than 150 nucleotides downstream of the $3^{\prime}$ ss have been transcribed (37). Two models have been proposed to explain how co-transcriptional splicing modulates AS. According to the "recruitment model" splicing factors are recruited to the nascent RNA molecule by the transcriptional apparatus (38-40) and can tether the $5^{\prime}$ ss of the intron to RNAPII until complete synthesis of the downstream exon (41). The "kinetic model," in contrast, assumes that the elongation rate of RNAPII defines the portion of the transcript that is available to the spliceosome and determines the pace at which relevant sequence elements, such as splice sites and regulatory elements, emerge from the transcriptional apparatus (42). It was initially suggested that a slow RNAPII would favor inclusion of an exon flanked by weak splice sites (43) (Figure 2C, Type I genes). It is now clear that slow elongation can also favor the recruitment of inhibitory splicing factors, in this manner promoting exon skipping (44) (Figure 2C, Type II genes). Thus, the effect of the elongation rate on splicing decisions (exon inclusion vs. exon skipping) actually depends on the gene context (45). The elongation rate of RNAPII ranges between 0.5 and $4 \mathrm{~kb} / \mathrm{min}$ and is influenced by exon density, CpG content and methylation pattern, and histone modifications (46) pointing to the importance of chromatin organization on AS. This is further suggested by the observation that the average exon length (132 nt) matches the nucleosome length (147 bp) (25). Genome wide approaches have shown that nucleosomes are preferentially positioned on exons with a CpG content higher than flanking introns and are rarely located over intronic regions close to splice sites $(47,48)$. This distribution pattern can account for the sensitivity of splicing programs to the activity of chromatin remodeling complexes, such as SWI/SNF and CDH $(49,50)$. It has been proposed that nucleosomes slow down the elongation rate of RNAPII and favor exon recognition by the splicing apparatus (51).

Altogether these analyses provided a completely new perspective to the field by introducing chromatin organization and the epigenetic code, namely the pattern of histone modifications, as major determinants in alternative splicing regulation (52). A large number of studies in the last 20 years have deciphered important aspects of the epigenetic code. Some histone modifications are predictive of the activity of gene promoters (53), while others, including H3K36me3 and $\mathrm{H} 3 \mathrm{~K} 27 \mathrm{me} 1 / 2 / 3$, are enriched in exons compared to introns $(47,54,55)$. The emerging picture is that exons are already defined at the chromatin level and that histone marks are directly implicated in the recruitment of splicing factors. This is the case of H3K4me3 that is bound by the chromatin remodeler $\mathrm{CDH} 1$, which in turn interacts with components of the spliceosome (50). Another example is H3K36me3 that preferentially marks constitutive exons while it is found at lower levels in alternatively spliced exons (56). This modification controls the splicing profile of numerous transcripts including the human fibroblast growth factor receptor 2 (FGFR2) gene transcripts, in this way affecting the Epithelial to Mesenchymal cell Transition (EMT). H3K36me3 is the landing pad for the chromodomaincontaining protein MRG15 (see Figure 2D), which, in turn, recognizes splicing regulator PTB/hnRNPI (52, 57). An additional H3K36me3 "reader" is Psip1, which recruits the SR factor SRSF1 (58). Splicing factors may also directly interact with nucleosomes. Thus, splicing factors SRSF3 and SRSF1 interact with unmodified histone $\mathrm{H} 3$, with $\mathrm{H} 3 \mathrm{~K} 9 \mathrm{Ac}$ and with H3K9Me. Interestingly, phosphorylation of histone H3 at Ser 10 during mitosis releases both splicing factors from chromatin, 


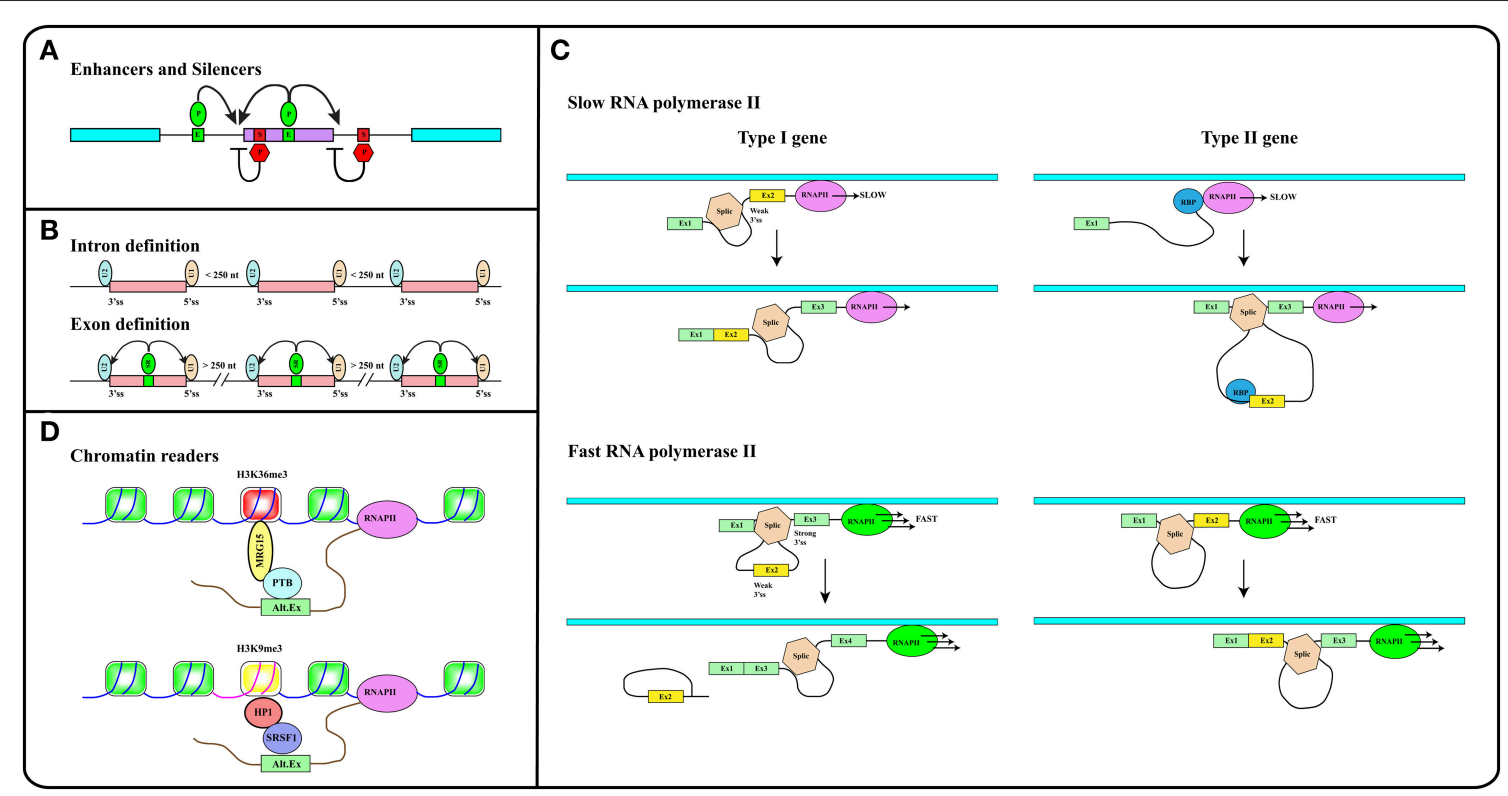

FIGURE 2 | (A) Splicing regulatory elements, enhancers (E, green boxes) and silencers (S, red boxes) are recognized by RNA binding proteins (P) that promote (green ovals) or inhibit (red hexagons) splice sites selection. (B) The intron definition mode accounts for the removal of short introns while exon definition explains splicing of long introns. SR factors (SR, green oval) bound to splicing enhancers (green box) promote the recruitment of snRNP particles U1 and U2 to exon boundaries. (C) The elongation rate of RNA polymerase II (RNAPII) determines the pace at which relevant sequence elements emerge from the transcriptional apparatus in this way affecting splicing decisions. In Type I genes, cassette exons (yellow) are included by slow and excluded by fast RNAPII. The opposite is true in the case of Type II genes. Cassette exons in Type I genes have weaker splice sites, shorter flanking introns, and distinct sequence motifs relative to those in Type II genes. Brown hexagon: spliceosome. Blue circle: RNA Binding Protein (RBP) that blocks the recognition of the $3^{\prime}$ splice site upstream of the cassette exon (see Text). (D) Histone modifications (e.g., H3K36me3 and H3K9me3 containing nucleosomes in red and yellow respectively) are recognized and bound by readers (e.g., MRG15, HP1) that in turn recruit splicing regulators (e.g., PTB, SRSF1) to modulate recognition of alternative exons. Methylation of gene body sequences (DNA in fuchsia instead of blue) promotes methylation of histone $\mathrm{H} 3$ at $\mathrm{K} 9$ leading to HP1 recruitment to internal exonic sequences.

in this way promoting the dissociation of HP1 from chromatin (59).

As discussed in excellent reviews, also DNA methylation can influence splicing profiles $(35,60)$. CpG methylation is nonrandomly distributed along the genome and specifically marks exons (48). Interestingly, in transcribed genes the CpG methylation pattern correlates strongly with H3K36me3 and inversely with H3K4me2 (61). DNA methylation modulates splicing of $22 \%$ of alternative exons. Three protein factors have been identified that can translate the information contained in the DNA methylation profile of gene bodies into AS regulation: (i) CTCF, (ii) $\mathrm{MeCP} 2$, and (iii) HP1. CTCF and MeCP2 directly read the methylation status of DNA and control gene expression. Although mainly characterized for their activity at gene promoters, these factors also bind the gene body and determine splicing of alternative exons. Notably, DNA methylation prevents the interaction of CTCF with exonic sequences, thus relieving the inhibitory effect of this factor on the elongation rate of RNAPII. In contrast, MeCP2 recruits histone deacetylases to methylated $\mathrm{CpG}$, in this manner promoting a close chromatin structure that leads to RNAPII pausing and exon inclusion. Thus, CpG methylation induces skipping of exons regulated by CTCF and inclusion of those bound by MeCP2 $(35,62,63)$. The involvement of HP1 in this circuitry is certainly more complex since the three HP1 proteins do not read the methylation status of $\mathrm{CpG}$ but interact with histone $\mathrm{H} 3 \mathrm{~K} 9 \mathrm{me} 3$. Interestingly, DNA methylation induces the $\mathrm{H} 3 \mathrm{~K} 9$ trimethylation creating a substrate for HP1 binding at the chromatin level. In turn, HP1 proteins recruit several splicing factors including SRSF3 (64) and SRSF1 (59) transferring the information from DNA methylation to splicing (Figure 2D).

\section{THE PKM CONNECTION}

The pyruvate kinase $\mathrm{M}(P K M)$ gene illustrates the impact that alternative splicing exerts on glucose metabolism. Pyruvate kinase $(\mathrm{PK})$ catalyzes a rate-limiting step of glycolysis in which a phosphate group is transferred from phosphoenolpyruvate (PEP) to ADP, leading to the production of one molecule of ATP and pyruvate (see Figure 1). PKs can also influence whether pyruvate is reduced to lactate by lactate dehydrogenase $(\mathrm{LDH})$ or oxidized to acetyl-CoA and $\mathrm{CO}_{2}$ by pyruvate dehydrogenase $(\mathrm{PDH})$, in this way fueling the Krebs cycle. Mammals have two $P K$ genes, $P K L R$ and $P K M$, each encoding two protein isoforms. While PKL and PKR are expressed in a tissue specific manner, the choice between PKM1 and PKM2 is mainly linked to cell proliferation vs. differentiation (65). 


\section{The Impact of PKM2 on Cell Growth and Glucose Metabolism}

PKM1 and PKM2 are generated through alternative splicing of mutually exclusive PKM exons 9 and 10 (Figure 3). Even though this switch produces a modest difference of only 22 out of 531 amino acids, the effects on protein and enzymatic properties are striking. PKM1 forms stable and constitutively active tetramers and promotes the channeling of pyruvate toward the Krebs cycle in order to meet the high energy needs of normal adult tissues such as the heart, brain, and skeletal muscle (67) (Figure 1). The expression of this isoform appears to be restricted to nonproliferating cells. However, only hypotheses have been raised to explain how PKM1 favors the oxidation of pyruvate to acetylCoA at the expense of lactate production.

Unlike PKM1, PKM2 can promote the conversion of glucose to lactate (68), a hallmark of the Warburg effect (Figure 1). PKM2 can form either tetramers or less active dimers that differ in their affinity for PEP, with $\mathrm{Km}$ values 0.03 and $0.46 \mathrm{mM}$ for the tetrameric and dimeric forms respectively. Although both complexes promote glycolysis, only dimeric PKM2, because of its low affinity for PEP, leads to accumulation of glycolytic intermediates, thereby providing cancer cells with substrates for anabolic processes (69). The choice between the two types of complexes is controlled by several allosteric effectors, by glucose metabolites and by post-translational modifications including phosphorylation by ERK1/2 (69-71). Moreover, PKM2, but not PKM1, can be inhibited by increased intracellular reactive oxygen species (ROS) (72) which may be produced during oxidative phosphorylation in mitochondria (73).

The impact of PKM2 on cell growth and glucose metabolism is twofold (67). As stated above, dimeric PKM2 promotes the Warburg effect, that is the shift of glucose metabolism from oxidative phosphorylation to glycolysis under normoxia (69). In addition, the PKM2 dimer is efficiently imported into the nucleus where it acts as a kinase that uses PEP as a phosphate donor to phosphorylate a number of proteins, including histone $\mathrm{H} 3$ at threonine (T) 11 (74). Interestingly, H3T11 phosphorylation, promotes subsequent $\mathrm{H} 3 \mathrm{~K} 9$ acetylation (74) which results in upregulation of MYC and cyclin D1 genes. In turn, MYC induces the expression of enzymes connected to aerobic glycolysis (71). Moreover, nuclear PKM2 directly regulates gene transcription by acting as a coactivator of hypoxiainducible factor-1 $\alpha$ (HIF1 $\alpha)$ under hypoxia (75) or $\beta$-catenin in response to EGF treatment (76) or by phosphorylating transcription factor Stat3 (77). Finally, by interacting with p53, PKM2 inhibits expression of p21 and allows proliferation of cancer cells in the presence of DNA damage (78). Altogether these properties make PKM2 more suitable than PKM1 to satisfy the anabolic requirements of rapidly proliferating cells (79). Not surprisingly, PKM2 expression is elevated in many types of cancers compared to normal tissues $(65,80,81)$, including colon and breast cancers $(82,83)$. Moreover, it is associated with poor prognosis in signet ring cell gastric cancer and esophageal squamous cell cancer $(84,85)$. The switch from PKM1 to PKM2 was observed in glioblastoma and breast cancer $(80,86)$.

\section{Splicing Factors Involved in Splicing of PKM Transcripts}

Because of their impact on cancer progression, the molecular mechanisms underlying the choice between $P K M$ exon 9 and 10 have been investigated by several groups leading to the identification of a group of relevant splicing factors. The general strategy that directs the PKM1/2 switch relies on two main elements: (1) hnRNPA1, hnRNPA2, and PTB/hnRNPI bind to sequences flanking $P K M 1$-specific exon 9 and inhibit its inclusion; (2) SR factor SRSF3 interacts with a splicing enhancer in $P K M 2$-specific exon 10 and promotes its inclusion (Figure 3) (87-90). The expression of the three hnRNP proteins is controlled by MYC. This is the basis of a self-sustaining circuit in which oncogenic transformation by MYC favors aerobic glycolysis by triggering the PKM2 specific splicing (88) and PKM2, in turn, induces the expression of MYC via histone H3 phosphorylation (71). Interestingly, PKM2 expression and glycolysis are under the control of the mTOR pathway and phosphorylation of hnRNPA1 at Ser6 by S6K2 kinase facilitates hnRNPA1 binding to PKM sequences (91) (Figure 3).

Additional splicing regulators have been shown to impact this general regulatory scheme. This is the case of NEK2, a serine/threonine kinase that phosphorylates splicing factor SRSF1 (92). It has been recently shown that NEK2 promotes skipping of PKM exon 9 and aerobic glycolysis through an interaction with hnRNPA1 and hnRNPA2 (66) (Figure 3).

Another example is RBM4, a splicing factor that links alternative splicing of $P K M$ transcripts to cell differentiation programs and cancer by antagonizing the function of PTB/hnRNPI (93). RBM4 acts at different levels. Upon binding a UCUU motif in PKM intron 8, RBM4 lessens the interaction of $\mathrm{PTB} / \mathrm{hnRNPI}$ with two UCUU motifs upstream of the $3^{\prime}$ splice site of the same intron, thus relieving the inhibitory effect played by PTB/hnRNPI on exon 9 inclusion (Figure 3). At the same time, it directly targets $\mathrm{PTB} / \mathrm{hnRNPI}$ expression and activity by modulating the splicing profile of PTBP1 gene transcripts. RBM4 induces skipping of PTBP1 exon 11, which results in the production of a mRNA isoform degraded by the nonsense-mediated RNA decay (NMD) pathway. Moreover, RBM4 promotes skipping of $P T B P 1$ exon 9 leading to the expression of a functional PTB/hnRNPI isoform showing a reduced repressive activity on splicing. The effects on PTB/hnRNPI are consistent with the important role of RBM4 in the activation of brainspecific AS programs, in neuronal differentiation and in the switch from aerobic glycolysis to oxidative phosphorylation (93-95).

Recently, also DNA methylation has been implicated in the choice between PKM exon 9 and 10 (86) through the CCCTCbinding factor like protein CTCFL/BORIS, an 11-zinc-finger factor. The analysis of paired breast tumor and adjacent normal tissues has revealed a higher PKM2 mRNA and protein level in the tumor tissue, which is accompanied by an increased DNA methylation at exon 10 and a significant enrichment of BORIS at the same exon (86). Inhibition of DNA methylation impairs binding of BORIS to PKM exon 10 and promotes the switch from the cancer-specific PKM2 to the PKM1 isoform. Mechanistically, 


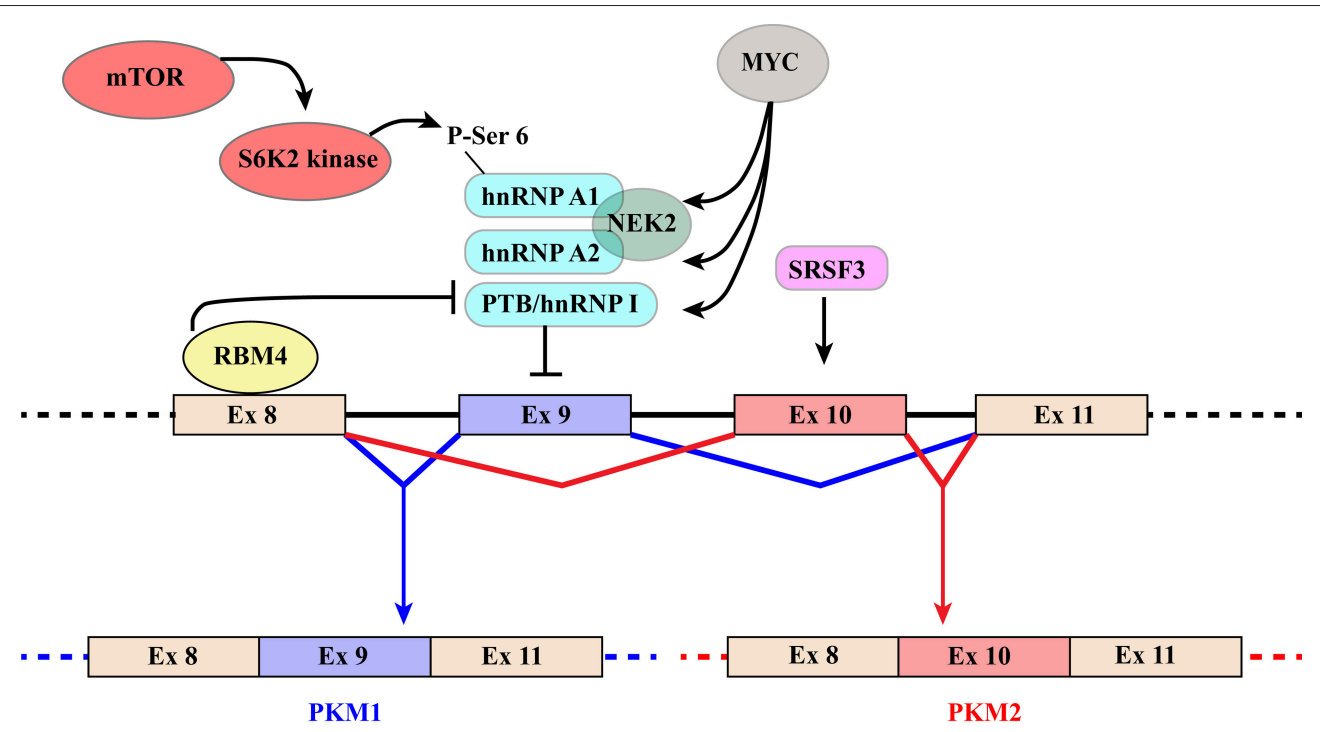

FIGURE 3 | Schematic representation of regulatory mechanisms that control the switch from PKM1 to PKM2. The diagram shows the region of the PKM gene that contains mutually exclusive exons 9 and 10, which are included in PKM1 and PKM2 transcripts, respectively. Recognition of exon 9 is inhibited by hnRNPA1, hnRNPA2, and PTB/hnRNP I that bind to regulatory elements flanking the exon. Several mechanisms contribute to increase skipping of exon9 and hence PKM2 production. The MYC oncogene exerts its influence by increasing the expression of the three hnRNP proteins. NEK2 kinase, whose expression is under the positive control of MYC (66), promotes PKM2 specific splicing through an interaction with hnRNPA1 and A2. In addition, phosphorylation of Ser6 of hnRNPA1 by S6K2 of the mTOR pathway facilitates hnRNPA1 binding to the splicing site of the PKM gene. Finally, selection of exon10 is promoted by splicing factor SRSF3. PKM1 production, in contrast, is induced by RBM4 that, upon binding to exon 8, inhibits the interaction of PTB/hnRNP I with regulatory elements controlling exon 9 splicing.

this involves a reduced accumulation of RNAPII at exon 10. The net effect is reversal of the Warburg effect and inhibition of breast cancer cell growth.

In contrast, high levels of PTB/hnRNPI promote proliferation, migration and invasion in clear-cell renal cell carcinoma cells in vitro by inducing the switch from PKM1 to PKM2. Notably, these effects are abolished upon PKM2 knockdown (96).

\section{2-OGDD SUPERFAMILY}

2-oxoglutarate-dependent dioxygenases (2-OGDD) form a superfamily of enzymes with a wide range of substrates including proteins, DNA and RNA. Not surprisingly, they influence several important aspects of cell biology. Their activities and functions have been discussed in several excellent reviews (97-100). These enzymes catalyze substrate hydroxylation in a reaction that is coupled to oxidative decarboxylation of $\alpha \mathrm{KG}$ $(\alpha$-ketoglutarate/2-oxoglutarate) to succinate, two intermediates of the Krebs cycle (Figure 4). The reaction depends on molecular oxygen as co-substrate and ferrous iron Fe(II) as a catalyzing cofactor. Thus, 2-OGDDs can be considered metabolic "sensors," since substrate hydroxylation is inhibited by low oxygen levels, by alterations in iron metabolism and by the $\alpha \mathrm{KG} /$ succinate ratio.

The level of specific intermediates of the Krebs cycle, such as the oncometabolites succinate and fumarate and their competitor $\alpha \mathrm{KG}$ is perturbed by mutations in crucial factors, with an impact on human health (101). An example is the isocitrate dehydrogenase (IDH) family that includes three members. IDHs catalyze the conversion of isocitrate to $\alpha \mathrm{KG}$ but only IDH3 operates during the Krebs cycle (102). Mutated IDH1 and 2 , which frequently occur in cancers such as gliomas and acute myeloid leukemia, allow the reduction of $\alpha \mathrm{KG}$ to 2hydroxyglutarate (2HG) (103). In patients bearing mutated IDH, $2 \mathrm{HG}$ accumulates at millimolar concentrations leading to pseudohypoxia, as revealed by $\mathrm{HIF} 1 \alpha$ stabilization. Moreover, high levels of $2 \mathrm{HG}$ inhibit a number of 2-OGDDs including JmjC domain-containing histone lysine demethylases and the TET family of 5-methylcytosine hydroxylases, thus impacting epigenetic regulation $(19,104)$. Although the increase in $\mathrm{CpG}$ methylation triggered by $2 \mathrm{HG}$ inhibits CTCF binding to DNA (105), the effect of IDH mutants on mRNA splicing profiles has not yet been investigated.

Also inactivating mutations in fumarate hydratase $(F H)$ and succinate dehydrogenase $(S D H)$ genes are causative of a subset of tumors (19) and produce fumarate and succinate accumulation to millimolar levels, far in excess of physiological concentrations (106, 107). Similarly to $2 \mathrm{HG}$, excess succinate and fumarate observed in $\mathrm{FH}$ and $\mathrm{SDH}$ mutants induce pseudohypoxia which stabilizes HIF1 $\alpha$ (108) and inhibits histone demethylases and TET enzymes (109-111).

Metabolic reprogramming in cancer cells can occur independently of the mutations described above, as for instance upon upregulation of the MYC oncogene. In addition to promoting aerobic glycolysis, MYC can stimulate the usage of glutamine as carbon and energy source. Indeed, MYC controls the expression of genes involved in glutaminolysis, in which glutamine through anaplerotic reactions is converted to $\alpha \mathrm{KG}$ 


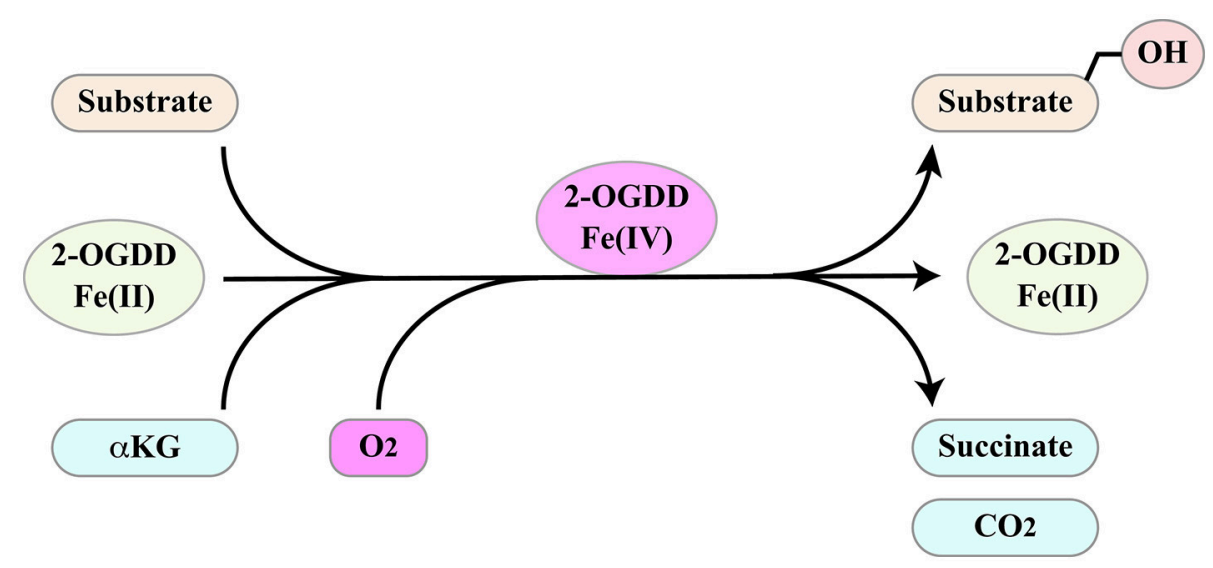

FIGURE 4 | 2-ODGGs catalyze the hydroxylation of a number of substrates. The reaction is coupled to oxidative decarboxylation of $\alpha$ KG ( $\alpha$-ketoglutarate/2-oxoglutarate) to succinate, two intermediates of the Krebs cycle, and depends on molecular oxygen as co-substrate and ferrous iron Fe(II) as a catalyzing cofactor.

and fuels the TCA cycle $(112,113)$. Moreover, MYC activates the expression of the tumor necrosis factor receptor-associated protein-1 (TRAP1) gene (114), a potent SDH inhibitor that induces succinate accumulation leading to pseudohypoxia (115).

2-OGDD enzymes share a catalytic domain that consists of a double-stranded $\beta$-helix (DSBH) core fold, frequently referred to as "jelly-roll" fold (116). Sequence comparison of the DSBH domains allowed the classification of 2-OGDDs in subfamilies (117). We mainly focus on the Jumonji-C (JmjC) domain-containing subfamily that comprises histone demethylases (KDM2-7) involved in the removal of methyl groups from specific methylated lysine $(\mathrm{K})$ of histones and JMJD6 involved in splicing regulation (118). We also discuss the TET family of 2-OGDDs that target 5-methylated cytosine $(5 \mathrm{mC})$ and demethylate DNA (119). Finally, we consider the ALKB family, comprising FTO and ALKBH5 RNA demethylases that catalyze demethylation of adenosine $\left(\mathrm{m}^{6} \mathrm{~A}\right)$ from nuclear RNA, which can be viewed as the RNA branch of the epigenetic program (120).

\section{KDMs Impact Splicing by Modulating Histone Methylation}

Histone methylation is determined by the antagonistic activity of histone methyltransferases (KMTs) and histone demethylases (KDMs) displaying different specificities in term of target residues and degree of modification, since $K$ residues in histone tails can be mono-, di-, or tri-methylated. The histone methylation pattern has an important role in regulation of gene transcription. In general, $\mathrm{H} 3 \mathrm{~K} 4, \mathrm{H} 3 \mathrm{~K} 36$, and $\mathrm{H} 3 \mathrm{~K} 79$ methylation is associated with active genes, whereas $\mathrm{H} 3 \mathrm{~K} 9$, $\mathrm{H} 3 \mathrm{~K} 27$, and H4K20 methylation correlates with transcriptional repression (121). Moreover, H3K4me3 is generally enriched in promoters, whereas $\mathrm{H} 3 \mathrm{~K} 79$ and $\mathrm{H} 3 \mathrm{~K} 36$ methylations are found within the gene body. With the notable exception of the flavin-dependent monoamine oxidases KDM1/LSD1, all KDMs belong to the JmjC-subfamily of 2-OGDDs. On the basis of the sequence of their JmjC-domain, KDMs have been grouped in 7 subfamilies called KDM 2 to 8 (Table 1). All these enzymes catalyze hydroxylation of ${ }^{\varepsilon} N$-methyl lysine leading to an unstable hemiaminal intermediate that spontaneously produces the demethylated lysine and formaldehyde (122). Each KDM displays a distinct methylation level and substrate specificity (see Table 1) (123). Moreover, KDMs show different affinities for molecular oxygen and $\alpha \mathrm{KG}(122,124)$. These features, along with the fact that some $K D M$ genes are transcriptionally activated by HIF1 (125), contribute to the complex reorganization of the histone methylation pattern in response to hypoxia. Like 2-OGDDs that control HIF1 $\alpha$ stability and activity, KDMs are inhibited by succinate and fumarate leading to an altered level of methylated histones (108). While the effect of KDMs activities on gene transcription and development is widely recognized, the impact on splicing programs is still largely unexplored. Probably the best example is provided by KDM2 that controls the splicing profile of FGFR2 transcripts (126) (Figure 5). The FGFR2 gene contains 2 mutually exclusive exons, IIIb and IIIc, which are differentially expressed in epithelial and mesenchymal cells. This splicing switch is driven by an epigenetic reorganization: $\mathrm{H} 3 \mathrm{~K} 36 \mathrm{me} 3$ and $\mathrm{H} 3 \mathrm{~K} 4 \mathrm{me} 1$ mark the alternatively spliced region in mesenchymal cells, where exon IIIc is included, while $\mathrm{H} 3 \mathrm{~K} 27 \mathrm{me} 3$ and $\mathrm{H} 3 \mathrm{~K} 4 \mathrm{me} 3$ are enriched in epithelial cells, where exon IIIb is selected (57). H3K36me3 inhibits selection of exon IIIb by recruiting the RNA binding protein PTB/hnRNPI to the nascent RNA via the adaptor factor MRG15. Interestingly, the establishment of the epigenetic landscape specific of epithelial cell, which impairs MRG15 binding and hence PTB/hnRNPI recruitment, relies on the expression of an antisense long noncoding RNA (lncRNA) generated from the human FGFR2 locus. This lncRNA mediates the recruitment of Polycomb-group proteins, which methylate histone $\mathrm{H} 3$ at $\mathrm{K} 27$, and the histone demethylase KDM2a, which erases H3K36me3 (126).

The role of RNA molecules in dictating the recruitment of KDM proteins to chromatin has been described also for KDM4D (127) adding a further layer of complexity to the system. It is plausible that lncRNAs may provide the specificity of action by bridging a specific KDM to a selected DNA sequence. 
TABLE 1 | Human 2-OGDDs with histone lysine demethylase activity.

\begin{tabular}{|c|c|c|}
\hline GENE NAME & NCBI ID & TARGET \\
\hline KDM2A & 22992 & H3K36me1/2 \\
\hline KDM2B & 84678 & $\begin{array}{l}\text { H3K4me3 } \\
\text { H3K36me2 }\end{array}$ \\
\hline KDM3A & 55818 & H3K9me2 \\
\hline KDM3B & 51780 & H3K9me1/2 \\
\hline KDM4A & 9682 & $\begin{array}{l}\mathrm{H} 3 \mathrm{~K} 9 \mathrm{me} 2 / 3 \\
\mathrm{H} 3 \mathrm{~K} 36 \mathrm{me} 2 / 3 \\
\mathrm{H} 4.1 \mathrm{~K} 26 \mathrm{me} 1 / 2 / 3\end{array}$ \\
\hline KDM4B & 23030 & $\begin{array}{l}\text { Н3К9me3 } \\
\text { Н3К36me3 }\end{array}$ \\
\hline KDM4C & 23081 & $\begin{array}{l}\text { H3K9me2/3 } \\
\text { H3K36me3 }\end{array}$ \\
\hline KDM4D & 55693 & H3K9me3 \\
\hline KDM4E & 390245 & H3K9me2/3 \\
\hline KDM5A & 5927 & H3K4me3 \\
\hline KDM5B & 10765 & $\mathrm{H} 3 \mathrm{~K} 4 \mathrm{me} 1 / 2 / 3$ \\
\hline KDM5C & 8242 & H3K4me3 \\
\hline KDM5D & 8284 & $\begin{array}{l}\text { H3K } 4 \text { me2/3 } \\
\text { Male specific }\end{array}$ \\
\hline KDM6A & 7403 & H3K27me3 \\
\hline KDM6B & 23135 & H3K27me2/3 \\
\hline KDM6C & 7404 & $\begin{array}{l}\text { H3K27me3 } \\
\text { Male specific }\end{array}$ \\
\hline KDM7A & 80853 & $\begin{array}{l}\text { H3K9me2 } \\
\text { H3K27me2 } \\
\text { H4K20me1 }\end{array}$ \\
\hline KDM7B & 23133 & $\begin{array}{l}\mathrm{H} 3 \mathrm{~K} 9 \mathrm{me} 1 / 2 \\
\mathrm{H} 4 \mathrm{~K} 20 \mathrm{me} 1\end{array}$ \\
\hline KDM7C & 5253 & H3K9me1 \\
\hline KDM8 & 79831 & H3K36me2 \\
\hline $\mathrm{RIOX} 1$ & 79697 & H3K36me3 \\
\hline $\mathrm{RIOX} 2$ & 84864 & H3K9me3 \\
\hline
\end{tabular}

A role in splicing regulation has been suggested also for KDM5B, which targets $\mathrm{H} 3 \mathrm{~K} 4 \mathrm{me} 3$. This enzyme regulates RNAPII promoter occupancy, transcriptional elongation and alternative splicing programs in embryonic stem (ES) cells. The effect on splicing decisions is partially explained by the impact of KDM5B on transcriptional elongation due to its ability to prevent $\mathrm{H} 3 \mathrm{~K} 4 \mathrm{me} 3$ spreading to the gene body. In addition, KDM5B is enriched nearby alternatively spliced cassette exons and its downregulation is accompanied by altered level of $\mathrm{H} 3 \mathrm{~K} 4 \mathrm{me} 3$ at alternatively spliced exons and by the differential expression of these exons (128). Interestingly, $\mathrm{H} 3 \mathrm{~K} 4 \mathrm{me} 3$ nucleosomes recruit $\mathrm{K}$-acetyltransferases (KATs) thus affecting the transcription elongation rate and pre-mRNA splicing of MCL1 transcript (129).

\section{Bifunctional Arginine Demethylase and Lysine Hydroxylase JMJD6}

The best example of a JmjC-domain-containing enzyme involved in AS regulation is JMJD6, whose structure and functions have been discussed in a recent review (16). Initially discovered as a phosphatidylserine receptor, subsequent sequence analysis identified JMJD6 as a member of the 2-OGDD superfamily (130).
Several studies have implicated JMJD6 in different types of cancer such as oral squamous cell carcinoma (OSCC), colon cancer, adenocarcinoma of the lung and breast cancer (131-134). In addition, JMJD6 cooperates with MYC in reducing the p53 level in breast cancer (135).

JMJD6 is a bifunctional arginine (R) demethylase and lysine (K) hydroxylase. It has been reported to demethylate histone $\mathrm{H} 3$ at R2 (H3R2) and histone H4 at R3 (H4R3) (136) and to hydroxylate $\mathrm{K}$ residues of several proteins including p53 (132) and a subset of splicing factors $(137,138)$. Mass spectrometry analysis proved that $\mathrm{U} 2$ small nuclear ribonucleoprotein auxiliary factor 65 (U2AF65) is lysyl-5-hydroxylated by JMJD6 at positions K15, K38 and K276 (137). While the lysyl-hydroxylase function has been validated, the activity of JMJD6 in arginine demethylation is still disputed.

JMJD6 is conserved from yeast to humans. It contains a classical JmjC domain that comprises binding sites for Fe(II) and $\alpha \mathrm{KG}$, an atypical AT-hook domain, three nuclear localization signal (NLS), one nuclear export sequence (NES) and a Cterminal poly-S domain that controls the subnuclear distribution of the protein (139). A splicing isoform lacking the poly-S domain is predominantly nucleolar. In addition to interacting with a large number of proteins [for a review see (16)], JMJD6 binds to single stranded RNA (ssRNA) but not to double-stranded RNA (dsRNA), ssDNA or dsDNA $(140,141)$. The interaction with RNA mediates the association of JMJD6 with SR factors (141) and probably involves the atypical extended AT-hook (eAThook) (142), in which the glycine-arginine-proline (GRP) core motif is extended with basic lysine and arginine residues in the C-terminal direction from the core but not in the N-terminal direction as in canonical eAT-hooks.

The strongest evidence in support of a role of JMJD6 in histone demethylation in living cells derives from the analysis of its interaction with the bromodomain-containing protein BRD4, a member of the bromodomain and extraterminal domain (BET) family of proteins. The JMJD6BRD4 complex regulates RNAPII promoter-proximal pause release by removing inhibitory factors, Hexim1 and 7SK snRNA, from the P-TEF complex. In this manner, it induces RNAPII phosphorylation and promotes the elongation phase of transcription. Critical for establishing promoter-proximal pausing is histone $\mathrm{H} 4$ dimethylated at $\mathrm{R} 3$ (H4R3me2) which is recognized and bound by the 7SK-Hexim 1 complex. The JMJD6-BRD4 complex disrupts this negative regulatory element by catalyzing demethylation of H4R3me2 and decapping of 7SK snRNA resulting in the displacement of Hexim1 (143). Whether this effect on transcription elongation influences alternative splicing patterns is still to be determined. However, it is worth noticing that BRD4 is implicated in splicing decision in response to stress treatments (144) and 7SK snRNA modulates splicing by controlling transcription elongation through the P-TEF complex (145). Interestingly, splicing factors of the SR family, including SRSF2, interact with the 7SK-Hexim 1 complex at gene promoters and release P-TEF and RNAPII from proximal-promoter pausing (146). It has been suggested that the recruitment of JMJD6 to gene body in a BRD4-dependent manner (147) could be important for proper RNA splicing. 


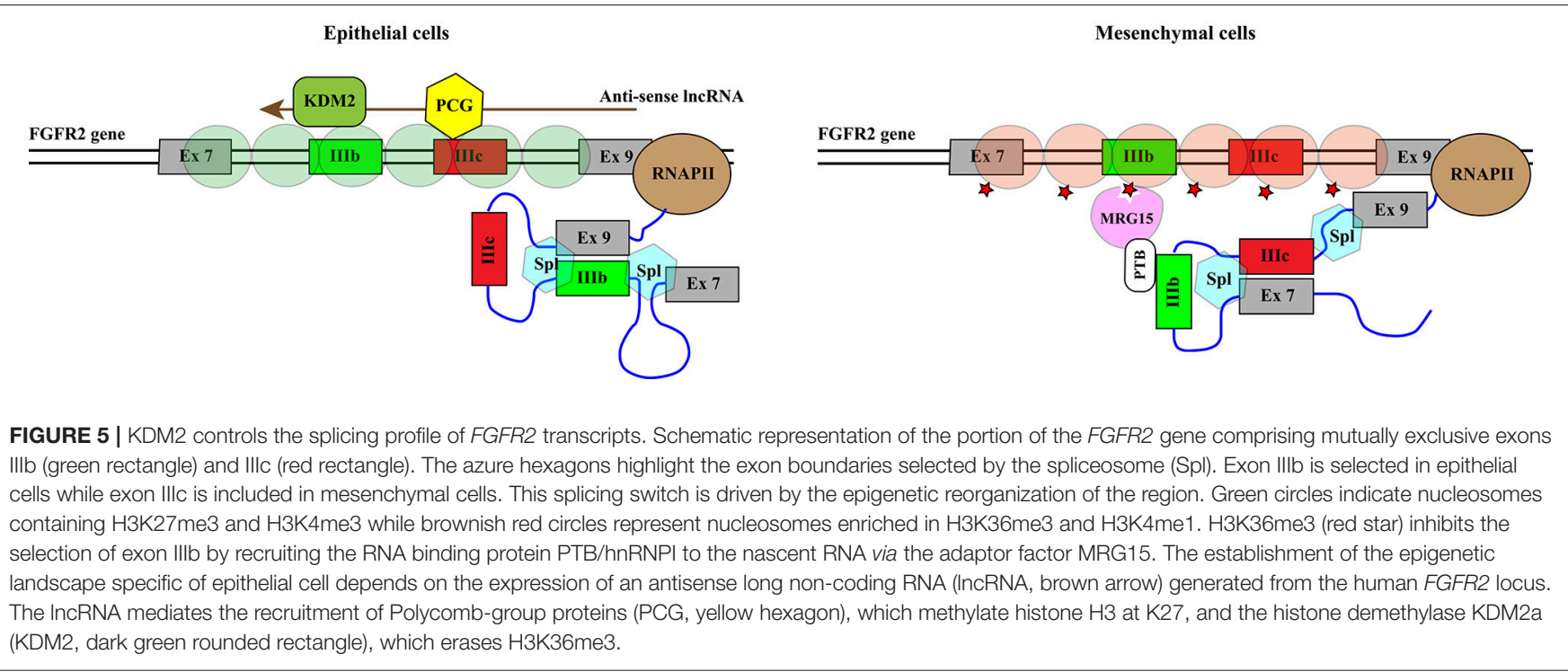

Another indication of the arginine demethylation activity of JMJD6 derives from the analysis of stress granules (SG), specific cytoplasmic structures assembled in response to different types of environmental stress. It has been shown that JMJD6 is involved in SG formation by reducing mono-methylation and asymmetric dimethylation of the SG component G3BP1 at three arginine residues (148).

JMJD6 interacts with several splicing factors, many of which contain RS domains (137, 141) (Figure 6B). However, with the exception of SRSF11, these interactors do not include "classical" SR factors (141). Notably, two of these RS domaincontaining proteins, namely U2AF65 and Luc7-like 2 factor (LUC7L2), are hydroxylated at lysine residues by JMJD6 (137). The reaction is $\alpha \mathrm{KG}$ - and $\mathrm{Fe}(\mathrm{II})$-dependent and is inhibited by Krebs cycle intermediates succinate and fumarate (137). Both U2AF65 and LUC7L2 are involved in splice site selection. $\mathrm{U} 2 \mathrm{AF} 65$ is required for $\mathrm{U} 2$ snRNP binding to the pre-mRNA branch point while LUC7L2 contributes to the recognition of non-consensus splice donor sites in association with U1 snRNP. In at least a subset of splicing events JMJD6 appears to act as an oxygen sensor. This is the case of vascular endothelial cell growth factor receptor 1 transcripts (VEGFR1, encoded by FLT1) (149). Reduced expression or activity of JMJD6 results in the production of a soluble VEGFR1 isoform which lacks the transmembrane and intracellular kinase domain and sequesters VEGF in unproductive complexes thus inhibiting angiogenesis. Critical for the effect on FLT1 pre-mRNA splicing is the interaction of JMJD6 with U2AF65. This mechanism operates in mouse placenta (150).

A significant fraction of alternative splicing events is coregulated by JMJD6 and U2AF65, suggesting a functional interaction between these two proteins (138). Several studies have investigated whether or not the enzymatic activity of JMJD6 is important for its function in AS regulation. However, the analysis of single genes has provided contradictory results
(137, 141, 149, 151). Recently, this issue has been addressed by genome-wide approaches (138) proving that approximately $60 \%$ of splicing events regulated by JMJD6 depend on the enzyme activity. Interestingly, a subset of JMJD6 and U2AF65 co-regulated alternative splicing events are linked to JMJD6mediated lysine hydroxylation of U2AF65 at K15, 38, and 276 and these modifications impact U2AF65 binding to RNA (Figure 6A). As expected from its role in splicing decisions, deregulation of JMJD6 function has important consequences on human health, and JMJD6 has been recently implicated in melanoma carcinogenesis through regulation of the alternative splicing of PAK1, a key MAPK signaling component (152).

\section{TET Proteins, DNA Methylation, and Alternative Splicing}

A number of studies have proven a link between DNA methylation and alternative splicing. The $\mathrm{CpG}$ methylation pattern is determined by antagonistic DNA methyltransferase (DNMT1, 3A, 3B, and 3L) and demethylase ten-eleven translocations (TET1-3) activities. TET proteins catalyze the successive oxidation of 5-methylcytosine $(5 \mathrm{mC})$ to 5 hydroxymethylcytosine $(5 \mathrm{hmC}), 5$-formylcytosine $(5 \mathrm{fC})$ and 5 -carboxylcytosine $(5 \mathrm{caC})(153,154)$, which are then rapidly removed by the action of thymine-DNA glycosylase (TDG) $(153,155)$. While a comparable level of $5 \mathrm{mC}$ is detectable in all tissues (approximately $5 \%$ of all Cs), oxidation products are significantly less abundant and their levels appear to be tissue specific. Thus, $5 \mathrm{hmC}$ peaks in the central nervous system $(<0.07 \%)$ while the abundance of $5 \mathrm{fC}$ and $5 \mathrm{caC}$ is at most 10 - to 100-fold lower [for a review see (156)]. In the last decade $5 \mathrm{hmC}$ has been shown to play a direct role in gene expression regulation by modulating the activity of promoters and transcriptional enhancers (157-159). More recently, this modification has been also proven to modulate alternative splicing $(62,160,161)$. Indeed, DNA methylation is enriched in cassette exons that are included in the mature mRNA, while it is 

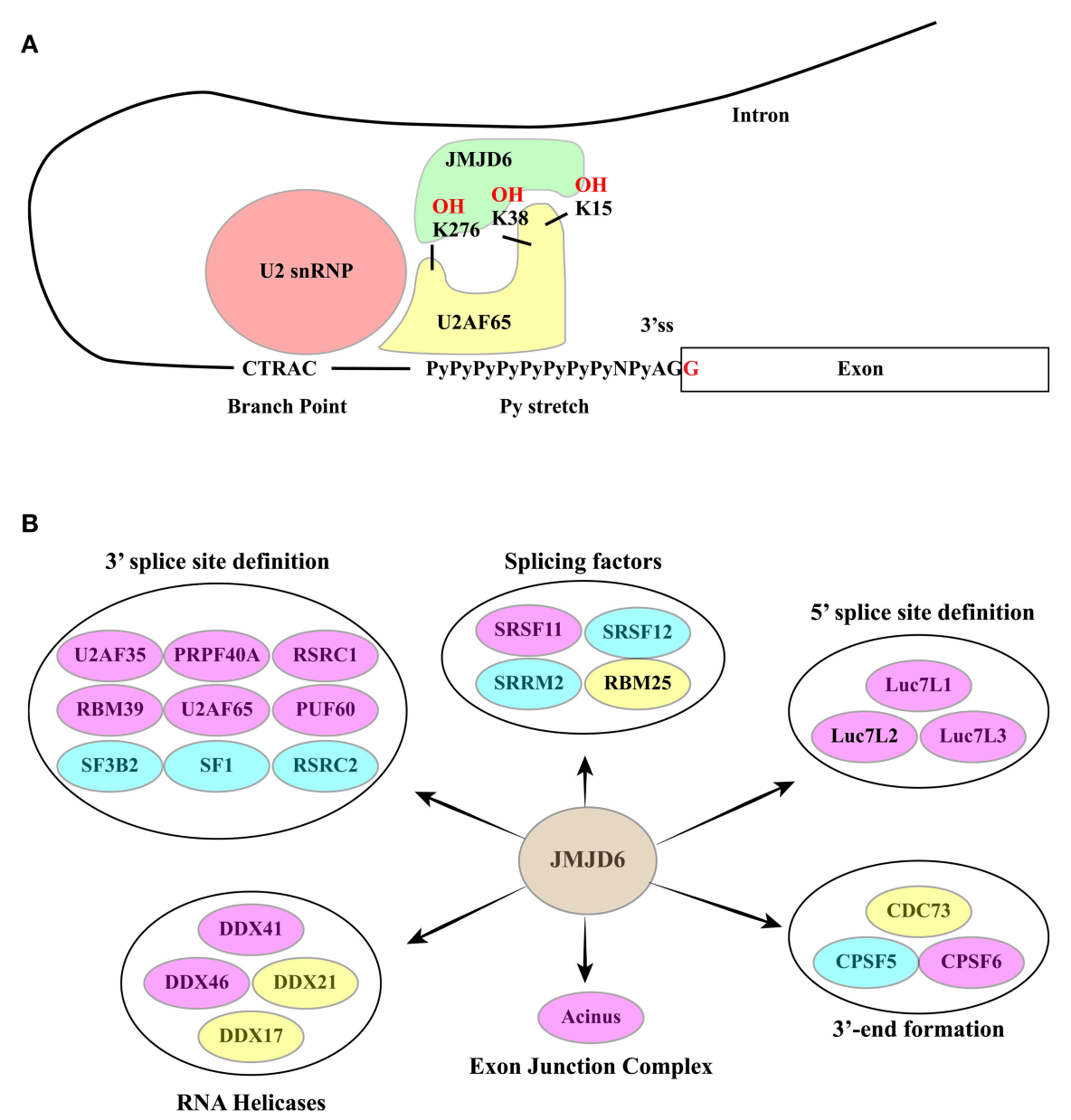

FIGURE 6 | (A) The RNA-dependent interaction between JMJD6 and U2AF65 is crucial for the ability of the two proteins to co-regulate alternative splicing events. JMJD6 promotes the interaction of U2AF65 with the Py-stretch that assists the recruitment of U2 snRNP to the branch point. At the same time U2AF65 induces binding of JMJD6 to RNA. The RNA sequence recognized and bound by JMJD6 is still to be identified. The ability of JMJD6 to regulate alternative splicing depends on its enzymatic activity and a subset of JMJD6 / U2AF65 co-regulated splicing events require JMJD6-mediated U2AF65 hydroxylation at K15, K38 and K276. (B) RNA processing factors shown to interact with JMJD6. Yellow ovals: interactors described in (137). Blue ovals: interactors described in Heim et al. (141). Pink Ovals: interactors identified by both studies. Interactors are grouped according to their function in splicing. A large group of interactors is formed by proteins involved in $3^{\prime}$ ss definition.

under-represented in skipped exons (62), in introns, intronless genes, and pseudoexons (60). The hypothesis that methylation "marks" exonic DNA for successive recognition of the nascent transcript by the spliceosome has been recently validated by the Oberdoerffer's group that identified the underlying molecular mechanism (161). Using the CD45 gene as model system, the authors showed that alternative splicing of a CD45 cassette exon is controlled by the methyl-sensitive zinc-finger protein CCCTC- binding factor (CTCF) whose interaction with DNA promotes RNAPII pausing and exon inclusion in naïve peripheral lymphocytes. The increased level of CpG methylation in the CD45 gene body, which occurs in activated lymphocytes, hampers CTCF binding and results in exon skipping. Crucial to this regulation, is the activity of TET1 and TET2 that declines during lymphocyte activation. These two factors catalyze $5 \mathrm{mC}$ oxidation to $5 \mathrm{hmC}$ and $5 \mathrm{caC}$ thus creating the binding site for
CTCF. It is known, in fact, that CTCF is a specific reader (162) that protects $5 \mathrm{caC}$ from the TDG activity (153). Interestingly, TDG downregulation increases the level of intragenic $5 \mathrm{caC}$ and reduces RNAPII elongation (163). Thus, TET-catalyzed oxidation of $5 \mathrm{mC}$ appears to control alternative splicing events in a CTCF-dependent manner. It is plausible that additional readers of $5 \mathrm{mC}$, or of the oxidized products generated by TET enzymes, may contribute to alternative splicing decisions (164). An example is $\mathrm{MeCP} 2$ that upon binding to $5 \mathrm{mC}$ modulates the alternative splicing programs of the BDNF transcripts (160).

TET enzymes belong to the large 2-OGDD superfamily (119, 165 ) and their activity is inhibited by succinate, fumarate, and hydroxyglutarate that accumulate in cell lines with mutated enzymes of the Krebs cycle [for a review see (100)]. For example, $5 \mathrm{hmC}$ is absent in nearly all gastrointestinal stromal tumors (GISTs) bearing a mutated succinate dehydrogenase $\mathrm{SDH}$ 
complex which leads to succinate accumulation (166). Thus, TETs act as sensors that modify the epigenetic organization in response to changes in the metabolic status of the cell. Intriguingly, these enzymes are induced by hypoxia, namely a condition that inhibits 2-OGDD activities. This paradox is explained by the fact that TET enzymes, thanks to their low Km for $\mathrm{O}_{2}$, can work even under low oxygen tension (109).

TET2 is mutated in several human cancers, including myeloid malignancies such as acute myeloid leukemia (AML) (167-169). In particular, AML frequently shows mutations that increase the $\mathrm{Km}$ of TETs for $\alpha \mathrm{KG}$ or produce higher level of fumarate and succinate (109). All these conditions inhibit TET activities and increase the level of $5 \mathrm{mC}$. Interestingly, genomic analysis of AML patients revealed frequent mutations in genes involved in epigenetic regulation (TET2, TET1, DNMT3A, and DNMT1) as well as mutations in splicing factor SFPQ and in the non-classic regulator of mRNA processing CTCF (170). A plausible hypothesis is that the disease involves a direct (mutation of splicing factors) or indirect ( $\mathrm{CpG}$ methylation pattern) perturbation of splicing programs. A similar association can be envisaged in myelodysplastic syndromes (MDS), a highly heterogenous group of hematopoietic tumors. The most common mutations detected in MDS patients occur in genes for RNA splicing (SF3B1, SRSF2, U2F1, ZRSR2) and DNA methylation factors (TET2, DNMT3A, IDH1/IDH2) $(171,172)$. This link between epigenetic and splicing factors is also suggested by the analysis of mastocytosis, a rare and chronic disease frequently caused by mutations in TET2 and SRSF2 genes (173, 174).

\section{$\mathrm{m}^{6} \mathrm{~A}$ : Signaling for mRNA Splicing}

Finally, we would like to briefly discuss the fact that specific 2-OGDDs may impact splicing by directly targeting gene transcripts. RNA molecules undergo a large number of chemical modifications. The most prevalent and also the only one shown to be reversible is methylation of adenosine at position N6 $\left(\mathrm{m}^{6} \mathrm{~A}\right)$. As in the case of DNA and histone modifications that determine the epigenetic organization of chromatin, writers, readers and erasers of $\mathrm{m}^{6} \mathrm{~A}$ have been identified, leading to the concept of epi-transcriptome (175). These studies also led to identify a loose consensus sequence (RRACH R = purine and $\mathrm{H}=\mathrm{A}, \mathrm{C}$, or $\mathrm{U}$ ) associated to this modification. In spite of this degeneracy, however, $\mathrm{m}^{6} \mathrm{~A}$ is particularly enriched in the $3^{\prime}$ untranslated regions ( $3^{\prime}$ UTRs) and within internal exons (176). This modification is established by the METTL3 METTL14 heterodimer (177) and erased by FTO (fat mass and obesity-associated) and ALKBH5, two demethylases belonging to the 2-OGDD superfamily $(178-180)$. Several $\mathrm{m}^{6} \mathrm{~A}$ readers have been identified, including nuclear YTHDC1/2 (181), cytoplasmic YTHDF1/2/3 (181) and nuclear hnRNPA2/B1 (182). The interaction between hnRNPA2/B1 and $\mathrm{m}^{6} \mathrm{~A}$ influences the splicing profile of target RNAs (182) while YTHDC1 affects splicing decisions by recruiting splicing factors of the SR family (183). A direct involvement of FTO and ALKBH5 demethylases in splicing has been demonstrated (179, 184-186). Studies in mice suggest a link between FTO, obesity and metabolic syndrome by driving obesity-prone behaviors (187).
Moreover, FTO-mediated $\mathrm{m}^{6} \mathrm{~A}$ demethylation controls splicing of adipogenic regulatory factor RUNX1T1 (184). However, both FTO and ALKBH5 are unlikely to work as $\alpha \mathrm{KG}$ sensors since the $\mathrm{Km}$ value of $2.88 \mu \mathrm{M}$ is up to 10 -fold lower than the estimated intracellular concentration of this intermediate of the Krebs cycle (188).

\section{CONCLUDING REMARKS AND THERAPEUTIC PERSPECTIVES}

Alterations in metabolism enable cancer cells to sustain their high proliferation rate. Oncoproteins and tumor suppressors have a major role in metabolic reprogramming $(20,189)$ and their unbalanced expression or mutation directly impacts the cell import of glucose and amino acids and the biosynthesis of macromolecules (190). Thus, both MYC and RAS promote glucose uptake and its utilization in aerobic glycolysis. However, they follow different strategies: RAS induces PKM2 phosphorylation by ERK resulting in the assembly of inefficient PKM2 dimers that shift glucose metabolism to glycolysis (191); MYC, in contrast, controls splicing of PKM transcripts promoting the switch from PKM1 to PKM2. In addition, it enhances the utilization of glutamine to fuel the Krebs cycle, a phenomenon known as glutamine "addiction" of cancer cells (112). Targeting the mechanisms underlying alterations of cell metabolism induced by an oncoprotein, therefore, can be a promising therapeutic strategy to treat tumors (192). Notably, MYC controls the expression of numerous proteins involved in RNA metabolism and splicing [for a review see (193)], which accounts for the sensitivity of MYC-driven tumors to pharmacological inhibition of splicing (194). This feature opens the possibility to use splicing factor effectors of MYC as target for therapeutic approaches (193, 195). Since hnRNPA1, hnRNPA2, PTB/hnRNPI are crucial for the MYC ability to modulate the PKM2/PKM1 ratio and cell metabolism, manipulation of their expression levels may be exploited for cancer therapy $(193,196,197)$. An alternative more promising strategy to manipulate the PKM2/PKM1 ratio is based on Anti Sense Oligonucleotides (ASO) designed to block the enhancer sequence in PKM exon 10 (198). Although the efficacy of this method in reducing PKM2 expression has been proven only in cultured cells, ASO have been successfully exploited to treat SMA $(199,200)$, a genetic disorder of the central nervous system. Thus, it is plausible that ASO may be tested also for treatment of glioblastoma and breast cancer in which the PKM1/PKM2 switch has been detected $(80,86)$.

In addition to being effectors of oncogenic pathways in controlling cell metabolism, splicing factors are targets of metabolic stress. Tumors are characterized by a significant microenvironmental heterogeneity, with some cells being in oxygen-rich districts and others distal to the blood vessels. Low oxygen tension activates HIF1. MYC collaborates with HIF1 to attenuate mitochondrial respiration and to increase glycolysis for adaptation to the tumor microenvironment. Moreover, HIF1 itself is able to orchestrate the reorganization of gene expression and splicing programs $(17,201)$. HIF1 increases the expression 
of CLK1, a kinase that specifically phosphorylates and modulates the activity of SR splicing factors (202). Thus, compounds able to modulate the activity of splicing kinases or splicing factors can be considered as possible approaches for inhibiting the response to hypoxia $(195,203,204)$ in tumors.

HIF1 activation is also induced by increased levels of oncometabolites (succinate, fumarate, $2 \mathrm{HG}$ ) which are generated by the Krebs cycle. This occurs in a subset of tumors due to mutations in specific metabolic enzymes. Mutated isocitrate dehydrogenase 1 , which produces the accumulation of D-2-hydroxyglutarate ( $2 \mathrm{HG})$, prevents the differentiation of erythroleukemia cells by affecting TET proteins, while mutations in succinate dehydrogenase $(\mathrm{SDH})$ and fumarate hydratase $(\mathrm{FH})$ are found in paragangliomas and pheochromocytomas, and leiomyomas and renal cell cancer, respectively [for a review see (19)]. Cell treatment with $\alpha \mathrm{KG}$ can counteract the effect of oncometabolites and reverse pseudohypoxia with anti-tumor and anti-angiogenic effects (205) although its impact on splicing profiles is still to be investigated.

The main question concerns how the metabolic status of the cells is detected and how sensors may modulate splicing decisions. Studies in the last 20 years have shown that members of the 2-OGDD superfamily have a role in this regulatory circuit and that their activity is modulated by intermediates of the Krebs cycle. These enzymes have the potential to impact splicing by targeting chromatin organization, components of the splicing machinery and the RNA molecule. However, their contribution to splicing programs is still largely unexplored, particularly in the

\section{REFERENCES}

1. Vander Heiden MG, Cantley LC, Thompson CB. Understanding the Warburg effect: the metabolic requirements of cell prolife ration. Science (2009) 324:1029-33. doi: 10.1126/science.1160809

2. Berg JM, Tymoczko JL, Stryer L. Biochemistry. New York, NY: W. H. Freeman (2010).

3. Hinkle PC, Kumar MA, Resetar A, Harris DL. Mechanistic stoichiometry of mitochondrial oxidative phosphorylation. Biochemistry (1991) 30:3576-82.

4. Warburg O. On the origin of cancer cells. Science (1956) 123:309-14.

5. Climente-González H, Porta-Pardo E, Godzik A, Eyras E. The Functional impact of alternative splicing in cancer. Cell Rep. (2017) 20:2215-26. doi: 10.1016/j.celrep.2017.08.012

6. Anczuków O, Krainer AR. Splicing-factor alterations in cancers. RNA (2016) 22:1285-301. doi: 10.1261/rna.057919.116

7. Zhang J, Manley JL. Misregulation of pre-mRNA alternative splicing in cancer. Cancer Discov. (2013) 3:1228-37. doi: 10.1158/2159-8290.CD-13-0253

8. Malcovati L, Papaemmanuil E, Bowen DT, Boultwood J, Porta Della MG, Pascutto C, et al. Clinical significance of SF3B1 mutations in myelodysplastic syndromes and myelodysplastic/myeloproliferative neoplasms. Blood (2011) 118:6239-46. doi: 10.1182/blood-2011-09-377275

9. Quesada V, Conde L, Villamor N, Ordóñez GR, Jares P, Bassaganyas L, et al. Exome sequencing identifies recurrent mutations of the splicing factor SF3B1 gene in chronic lymphocytic leukemia. Nat Genet. (2011) 44:47-52. doi: $10.1038 /$ ng. 1032

10. Chabot B, Shkreta L. Defective control of pre-messenger RNA splicing in human disease. J Cell Biol. (2016) 212:13-27. doi: 10.1083/jcb.201510032

11. Biamonti G, Catillo M, Pignataro D, Montecucco A, Ghigna C. The alternative splicing side of cancer. Semin Cell Dev Biol. (2014) 32:30-6. doi: 10.1016/j.semcdb.2014.03.016 case of KDM proteins that modulate the histone code. Thus, for instance, the mechanisms conferring specificity to KDM proteins are still to be deciphered. It is likely that long non-coding RNA may have a role in this phenomenon (126), adding a further level of complexity in this regulatory circuit. Moreover, very few transcriptomic analyses have been performed so far to investigate the impact of 2-OGDDs on splicing decision. Because of the relevance to several important human diseases, such as diabetes, cancer and neurological disorders, the dissection of the link between glucose metabolism and alternative splicing in the next few years is conceivable to open new perspectives of therapeutic intervention.

\section{AUTHOR CONTRIBUTIONS}

GB and AM designed and wrote the manuscript. All the authors revised and approved the manuscript.

\section{ACKNOWLEDGMENTS}

We sincerely apologize to authors whose original works have not been cited here. This work has been supported by grants from Associazione Italiana per la Ricerca sul Cancro AIRC (grant number 15273), Flagship project InterOmics (CNR-MIUR) and Progetto d'Interesse Invecchiamento (CNRMIUR) to GB. LM has been supported by a fellowship of the AMANDA project Accordo Quadro Regione Lombardia-CNR.
12. Kozlovski I, Siegfried Z, Amar-Schwartz A, Karni R. The role of RNA alternative splicing in regulating cancer metabolism. Hum Genet. (2017) 136:1113-27. doi: 10.1007/s00439-017-1803-x

13. Singh B, Eyras E. The role of alternative splicing in cancer. Transcription (2017) 8:91-8. doi: 10.1080/21541264.2016.1268245

14. Gonçalves V, Pereira JFS, Jordan P. Signaling pathways driving aberrant splicing in cancer cells. Genes (Basel) (2017) 9:9. doi: 10.3390/genes9010009

15. Abou Faycal C, Gazzeri S, Eymin B. RNA splicing, cell signaling, and response to therapies. Curr Opin Oncol. (2016) 28:58-64. doi: 10.1097/CCO.0000000000000254

16. Kwok J, O’Shea M, Hume DA, Lengeling A. Jmjd6, a JmjC Dioxygenase with many interaction partners and pleiotropic functions. Front Genet. (2017) 8:32. doi: 10.3389/fgene.2017.00032

17. Kanopka A. Cell survival: interplay between hypoxia and pre-mRNA splicing. Exp Cell Res. (2017) 356:187-91. doi: 10.1016/j.yexcr.2017.03.018

18. Oltean S, Bates DO. Hallmarks of alternative splicing in cancer. Oncogene (2013) doi: 10.1038/onc.2013.533

19. Zhou Z, Ibekwe E, Chornenkyy Y. Metabolic alterations in cancer cells and the emerging role of oncometabolites as drivers of neoplastic change. Antioxidants (Basel) (2018) 7:16. doi: 10.3390/antiox7010016

20. Vander Heiden MG, DeBerardinis RJ. Understanding the intersections between metabolism and cancer biology. Cell (2017) 168:657-69. doi: 10.1016/j.cell.2016.12.039

21. Lu C, Thompson CB. Metabolic regulation of epigenetics. Cell Metab. (2012) 16:9-17. doi: 10.1016/j.cmet.2012.06.001

22. Wu B, Li L, Huang Y, Ma J, Min J. Readers, writers and erasers of N6methylated adenosine modification. Curr Opin Struct Biol. (2017) 47:67-76. doi: 10.1016/j.sbi.2017.05.011

23. Cai L, Sutter BM, Li B, Tu BP. Acetyl-CoA induces cell growth and proliferation by promoting the acetylation of histones at growth genes. Mol Cell (2011) 42:426-37. doi: 10.1016/j.molcel.2011.05.004 
24. Will CL, Lührmann R. Spliceosome structure and function. Cold Spring Harb Perspect Biol. (2011) 3:a003707. doi: 10.1101/cshperspect.a003707

25. Gelfman S, Burstein D, Penn O, Savchenko A, Amit M, Schwartz S, Pupko T, Ast G. Changes in exon-intron structure during vertebrate evolution affect the splicing pattern of exons. Genome Res. (2012) 22:35-50. doi: 10.1101/gr.119834.110

26. Kornblihtt AR, Schor IE, Allo M, Dujardin G, Petrillo E, Muñoz MJ. Alternative splicing: a pivotal step between eukaryotic transcription and translation. Nat Rev Mol Cell Biol. (2013) 14:153-65. doi: 10.1038/nrm3525

27. Pan Q, Shai O, Lee LJ, Frey BJ, Blencowe BJ. Deep surveying of alternative splicing complexity in the human transcriptome by high-throughput sequencing. Nat Genet. (2008) 40:1413-5. doi: 10.1038/ng.259

28. Montecucco A, Biamonti G. Pre-mRNA processing factors meet the DNA damage response. Front Genet. (2013) 4:102. doi: 10.3389/fgene.2013.00102

29. Naftelberg S, Schor IE, Ast G, Kornblihtt AR. Regulation of alternative splicing through coupling with transcription and chromatin structure. Annu Rev Biochem. (2015) 84:165-98. doi: 10.1146/annurev-biochem-060614-034242

30. Herzel L, Ottoz DSM, Alpert T, Neugebauer KM. Splicing and transcription touch base: co-transcriptional spliceosome assembly and function. Nat Rev Mol Cell Biol. (2017) 18:637-50. doi: 10.1038/nrm.2017.63

31. Barash Y, Calarco JA, Gao W, Pan Q, Wang X, Shai O, Blencowe BJ, Frey BJ. Deciphering the splicing code. Nature (2010) 465:53-9. doi: $10.1038 /$ nature09000

32. Jelen N, Ule J, Zivin M, Darnell RB. Evolution of Nova-dependent splicing regulation in the brain. PLoS Genet. (2007) 3:1838-47. doi: 10.1371/journal.pgen.0030173

33. Lee J-A, Tang Z-Z, Black DL. An inducible change in Fox-1/A2BP1 splicing modulates the alternative splicing of downstream neuronal target exons. Genes Dev. (2009) 23:2284-93. doi: 10.1101/gad.1837009

34. Han H, Braunschweig U, Gonatopoulos-Pournatzis T, Weatheritt RJ, Hirsch CL, Ha KCH, et al. Multilayered control of alternative splicing regulatory networks by transcription factors. Mol Cell (2017) 65:539-53.e7. doi: 10.1016/j.molcel.2017.01.011

35. Lev-Maor G, Yearim A, Ast G. The alternative role of DNA methylation in splicing regulation. Trends Genet. (2015) 31:274-80. doi: 10.1016/j.tig.2015.03.002

36. Tilgner H, Knowles DG, Johnson R, Davis CA, Chakrabortty S, Djebali S, et al. Deep sequencing of subcellular RNA fractions shows splicing to be predominantly co-transcriptional in the human genome but inefficient for lncRNAs. Genome Res. (2012) 22:1616-25. doi: 10.1101/gr.134445.111

37. Oesterreich FC, Herzel L, Straube K, Hujer K, Howard J, Neugebauer KM. Splicing of Nascent RNA Coincides with Intron Exit from RNA Polymerase II. Cell (2016) 165:372-81. doi: 10.1016/j.cell.2016.02.045

38. McCracken S, Fong N, Yankulov K, Ballantyne S, Pan G, Greenblatt J, et al. The C-terminal domain of RNA polymerase II couples mRNA processing to transcription. Nature (1997) 385:357-61. doi: 10.1038/385357a0

39. Misteli T, Spector DL. RNA polymerase II targets pre-mRNA splicing factors to transcription sites in vivo. Mol Cell (1999) 3:697-705.

40. Ujvári A, Luse DS. Newly Initiated RNA encounters a factor involved in splicing immediately upon emerging from within RNA polymerase II. J Biol Chem. (2004) 279:49773-9. doi: 10.1074/jbc.M409087200

41. Hollander D, Naftelberg S, Lev-Maor G, Kornblihtt AR, Ast G. How are short exons flanked by long introns defined and committed to splicing? Trends Genet. (2016) 32:596-606. doi: 10.1016/j.tig.2016. 07.003

42. Nogues G, Kadener S, Cramer P, Bentley D, Kornblihtt AR. Transcriptional activators differ in their abilities to control alternative splicing. J Biol Chem. (2002) 277:43110-4. doi: 10.1074/jbc.M208418200

43. la Mata de M, Lafaille C, Kornblihtt AR. First come, first served revisited: factors affecting the same alternative splicing event have different effects on the relative rates of intron removal. RNA (2010) 16:904-12. doi: 10.1261/rna.1993510

44. Ip JY, Schmidt D, Pan Q, Ramani AK, Fraser AG, Odom DT, Blencowe BJ. Global impact of RNA polymerase II elongation inhibition on alternative splicing regulation. Genome Res. (2011) 21:390-401. doi: $10.1101 /$ gr.111070.110
45. Fong N, Kim H, Zhou Y, Ji X, Qiu J, Saldi T, et al. Pre-mRNA splicing is facilitated by an optimal RNA polymerase II elongation rate. Genes Dev. (2014) 28:2663-76. doi: 10.1101/gad.252106.114

46. Jonkers I, Kwak H, Lis JT. Genome-wide dynamics of Pol II elongation and its interplay with promoter proximal pausing, chromatin, and exons. Elife (2014) 3:e02407. doi: 10.7554/eLife.02407

47. Schwartz S, Meshorer E, Ast G. Chromatin organization marks exon-intron structure. Nat Struct Mol Biol. (2009) 16:990-5. doi: 10.1038/nsmb.1659

48. Chodavarapu RK, Feng S, Bernatavichute YV, Chen P-Y, Stroud H, Yu Y, et al. Relationship between nucleosome positioning and DNA methylation. Nature (2010) 466:388-92. doi: 10.1038/nature09147

49. Batsché E, Yaniv M, Muchardt C. The human SWI/SNF subunit Brm is a regulator of alternative splicing. Nat Struct Mol Biol. (2006) 13:22-9. doi: $10.1038 / \mathrm{nsmb} 1030$

50. Sims RJ, Millhouse S, Chen C-F, Lewis BA, Erdjument-Bromage H, et al. Recognition of trimethylated histone $\mathrm{H} 3$ lysine 4 facilitates the recruitment of transcription postinitiation factors and pre-mRNA splicing. Mol Cell (2007) 28:665-76. doi: 10.1016/j.molcel.2007.11.010

51. Schwartz S, Ast G. Chromatin density and splicing destiny: on the crosstalk between chromatin structure and splicing. EMBO J. (2010) 29:1629-36. doi: 10.1038/emboj.2010.71

52. Luco RF, Allo M, Schor IE, Kornblihtt AR, Misteli T. Epigenetics in alternative pre-mRNA splicing. Cell (2011) 144:16-26. doi: 10.1016/j.cell.2010.11.056

53. Karlić R, Chung H-R, Lasserre J, Vlahovicek K, Vingron M. Histone modification levels are predictive for gene expression. Proc Natl Acad Sci USA. (2010) 107:2926-31. doi: 10.1073/pnas.0909344107

54. Spies N, Nielsen CB, Padgett RA, Burge CB. Biased chromatin signatures around polyadenylation sites and exons. Mol Cell (2009) 36:245-54. doi: 10.1016/j.molcel.2009.10.008

55. Hon GC, Hawkins RD, Ren B. Predictive chromatin signatures in the mammalian genome. Hum Mol Genet. (2009) 18:R195-201. doi: 10.1093/hmg/ddp409

56. Kolasinska-Zwierz P, Down T, Latorre I, Liu T, Liu XS, Ahringer J. Differential chromatin marking of introns and expressed exons by H3K36me3. Nat Genet. (2009) 41:376-81. doi: 10.1038/ng.322

57. Luco RF, Pan Q, Tominaga K, Blencowe BJ, Pereira-Smith OM, Misteli T. Regulation of alternative splicing by histone modifications. Science (2010) 327:996-1000. doi: 10.1126/science.1184208

58. Pradeepa MM, Sutherland HG, Ule J, Grimes GR, Bickmore WA. Psip1/Ledgf p52 binds methylated histone H3K36 and splicing factors and contributes to the regulation of alternative splicing. PLoS Genet. (2012) 8:e1002717. doi: 10.1371/journal.pgen.1002717

59. Loomis RJ, Naoe Y, Parker JB, Savic V, Bozovsky MR, Macfarlan T, Manley JL, Chakravarti D. Chromatin binding of SRp20 and ASF/SF2 and dissociation from mitotic chromosomes is modulated by histone H3 serine 10 phosphorylation. Mol Cell (2009) 33:450-61. doi: 10.1016/j.molcel.2009.02.003

60. Gelfman S, Ast G. When epigenetics meets alternative splicing: the roles of DNA methylation and GC architecture. Epigenomics (2013) 5:351-3. doi: $10.2217 /$ epi.13.32

61. Hodges E, Smith AD, Kendall J, Xuan Z, Ravi K, Rooks M, et al. High definition profiling of mammalian DNA methylation by array capture and single molecule bisulfite sequencing. Genome Res. (2009) 19:1593-605. doi: 10.1101/gr.095190.109

62. Maunakea AK, Chepelev I, Cui K, Zhao K. Intragenic DNA methylation modulates alternative splicing by recruiting MeCP2 to promote exon recognition. Cell Res. (2013) 23:1256-69. doi: 10.1038/cr.2013.110

63. Shukla S, Kavak E, Gregory M, Imashimizu M, Shutinoski B, Kashlev M, et al. CTCF-promoted RNA polymerase II pausing links DNA methylation to splicing. Nature (2011) 479:74-9. doi: 10.1038/nature10442

64. Yearim A, Gelfman S, Shayevitch R, Melcer S, Glaich O, Mallm J-P, et al. HP1 is involved in regulating the global impact of DNA methylation on alternative splicing. Cell Rep. (2015) 10:1122-34. doi: 10.1016/j.celrep.2015.01.038

65. Bluemlein K, Grüning N-M, Feichtinger RG, Lehrach H, Kofler B, Ralser M. No evidence for a shift in pyruvate kinase PKM1 to PKM2 expression during tumorigenesis. Oncotarget (2011) 2:393-400. doi: 10.18632/oncotarget.278 
66. Gu Z, Xia J, Xu H, Frech I, Tricot G, Zhan F. NEK2 promotes aerobic glycolysis in multiple myeloma through regulating splicing of pyruvate kinase. J Hematol Oncol. (2017) 10:17. doi: 10.1186/s13045-017-0392-4

67. Israelsen WJ, Vander Heiden MG. Pyruvate kinase: Function, regulation and role in cancer. Semin Cell Dev Biol. (2015) 43:43-51. doi: 10.1016/j.semcdb.2015.08.004

68. Christofk HR, Vander Heiden MG, Harris MH, Ramanathan A, Gerszten $\mathrm{RE}$, Wei R, et al. The M2 splice isoform of pyruvate kinase is important for cancer metabolism and tumour growth. Nature (2008) 452:230-3. doi: 10.1038 /nature06734

69. Mazurek S. Pyruvate kinase type M2: a key regulator of the metabolic budget system in tumor cells. Int J Biochem Cell Biol. (2011) 43:969-80. doi: 10.1016/j.biocel.2010.02.005

70. Chaneton B, Hillmann P, Zheng L, Martin ACL, Maddocks ODK, Chokkathukalam A, et al. Serine is a natural ligand and allosteric activator of pyruvate kinase M2. Nature (2012) 491:458-62. doi: 10.1038/nature11540

71. Yang W, Lu Z. Nuclear PKM2 regulates the Warburg effect. Cell Cycle (2013) 12:3154-8. doi: $10.4161 /$ cc.26182

72. Anastasiou D, Poulogiannis G, Asara JM, Boxer MB, Jiang J-K, Shen $\mathrm{M}$, et al. Inhibition of pyruvate kinase $\mathrm{M} 2$ by reactive oxygen species contributes to cellular antioxidant responses. Science (2011) 334:1278-83. doi: $10.1126 /$ science. 1211485

73. Pignataro D, Francia S, Zanetta F, Brenna G, Brandini S, Olivieri A, et al. A missense MT-ND5 mutation in differentiated Parkinson Disease cytoplasmic hybrid induces ROS-dependent DNA Damage Response amplified by DROSHA. Sci Rep. (2017) 7:9528. doi: 10.1038/s41598-01709910-x

74. Yang W, Xia Y, Hawke D, Li X, Liang J, Xing D, et al. PKM2 phosphorylates histone $\mathrm{H} 3$ and promotes gene transcription and tumorigenesis. Cell (2012) 150:685-96. doi: 10.1016/j.cell.2012.07.018

75. Luo W, Hu H, Chang R, Zhong J, Knabel M, O’Meally R, et al. Pyruvate kinase M2 is a PHD3-stimulated coactivator for hypoxia-inducible factor 1. Cell (2011) 145:732-44. doi: 10.1016/j.cell.2011.03.054

76. Gao X, Wang H, Yang JJ, Chen J, Jie J, Li L, et al. Reciprocal regulation of protein kinase and pyruvate kinase activities of pyruvate kinase M2 by growth signals. J Biol Chem. (2013) 288:15971-9. doi: 10.1074/jbc.M112.448753

77. Gao X, Wang H, Yang JJ, Liu X, Liu Z-R. Pyruvate kinase M2 regulates gene transcription by acting as a protein kinase. Mol Cell (2012) 45:598-609. doi: 10.1016/j.molcel.2012.01.001

78. Xia L, Wang X-R, Wang X-L, Liu S-H, Ding X-W, Chen G-Q, et al. A novel role for pyruvate kinase M2 as a corepressor for P53 during the DNA damage response in human tumor cells. J Biol Chem. (2016) 291:26138-50. doi: 10.1074/jbc.M116.737056

79. Lunt SY, Muralidhar V, Hosios AM, Israelsen WJ, Gui DY, Newhouse L, et al. Pyruvate kinase isoform expression alters nucleotide synthesis to impact cell proliferation. Mol Cell (2015) 57:95-107. doi: 10.1016/j.molcel.2014.10.027

80. Desai S, Ding M, Wang B, Lu Z, Zhao Q, Shaw K, et al. Tissuespecific isoform switch and DNA hypomethylation of the pyruvate kinase PKM gene in human cancers. Oncotarget (2014) 5:8202-10. doi: 10.18632/oncotarget.1159

81. Israelsen WJ, Dayton TL, Davidson SM, Fiske BP, Hosios AM, Bellinger G, et al. PKM2 isoform-specific deletion reveals a differential requirement for pyruvate kinase in tumor cells. Cell (2013) 155:397-409. doi: 10.1016/j.cell.2013.09.025

82. Eigenbrodt E, Basenau D, Holthusen S, Mazurek S, Fischer G. Quantification of tumor type M2 pyruvate kinase (Tu M2-PK) in human carcinomas. Anticancer Res. (1997) 17:3153-6.

83. Lüftner D, Mesterharm J, Akrivakis C, Geppert R, Petrides PE, Wernecke KD, et al. Tumor type M2 pyruvate kinase expression in advanced breast cancer. Anticancer Res. (2000) 20:5077-82.

84. Lim JY, Yoon SO, Seol SY, Hong SW, Kim JW, Choi SH, et al. Overexpression of the M2 isoform of pyruvate kinase is an adverse prognostic factor for signet ring cell gastric cancer. World J Gastroenterol. (2012) 18:4037-43. doi: 10.3748/wjg.v18.i30.4037

85. Zhan C, Shi Y, Lu C, Wang Q. Pyruvate kinase M2 is highly correlated with the differentiation and the prognosis of esophageal squamous cell cancer. Dis Esophagus (2013) 26:746-53. doi: 10.1111/dote.12023
86. Singh S, Narayanan SP, Biswas K, Gupta A, Ahuja N, Yadav S, et al. Intragenic DNA methylation and BORIS-mediated cancer-specific splicing contribute to the Warburg effect. Proc Natl Acad Sci USA. (2017) 114:114405. doi: 10.1073/pnas.1708447114

87. Chen M, David CJ, Manley JL. Concentration-dependent control of pyruvate kinase M mutually exclusive splicing by hnRNP proteins. Nat Struct Mol Biol. (2012) 19:346-54. doi: 10.1038/nsmb.2219

88. David CJ, Chen M, Assanah M, Canoll P, Manley JL. HnRNP proteins controlled by c-Myc deregulate pyruvate kinase mRNA splicing in cancer. Nature (2010) 463:364-8. doi: 10.1038/nature08697

89. Wang Z, Chatterjee D, Jeon HY, Akerman M, Vander Heiden MG, Cantley LC, et al. Exon-centric regulation of pyruvate kinase $\mathrm{M}$ alternative splicing via mutually exclusive exons. J Mol Cell Biol. (2012) 4:79-87. doi: $10.1093 / \mathrm{jmcb} / \mathrm{mjr} 030$

90. Clower CV, Chatterjee D, Wang Z, Cantley LC, Vander Heiden MG, Krainer AR. The alternative splicing repressors hnRNP A1/A2 and PTB influence pyruvate kinase isoform expression and cell metabolism. Proc Natl Acad Sci USA. (2010) 107:1894-9. doi: 10.1073/pnas.0914845107

91. Sun Y, Luo M, Chang G, Ren W, Wu K, Li X, et al. Phosphorylation of Ser6 in hnRNPA1 by S6K2 regulates glucose metabolism and cell growth in colorectal cancer. Oncol Lett. (2017) 14:7323-31. doi: 10.3892/ol.2017.7085

92. Naro C, Barbagallo F, Chieffi P, Bourgeois CF, Paronetto MP, Sette C. The centrosomal kinase NEK2 is a novel splicing factor kinase involved in cell survival. Nucleic Acids Res. (2014) 42:3218-27. doi: 10.1093/nar/gkt1307

93. Su C-H, Hung K-Y, Hung S-C, Tarn W-Y. RBM4 regulates neuronal differentiation of mesenchymal stem cells by modulating alternative splicing of pyruvate kinase M. Mol Cell Biol. (2017) 37:e00466-16. doi: 10.1128/MCB.00466-16

94. Zheng X, Boyer L, Jin M, Mertens J, Kim Y, Ma L, et al. Metabolic reprogramming during neuronal differentiation from aerobic glycolysis to neuronal oxidative phosphorylation. Elife (2016) 5:859. doi: $10.7554 /$ eLife. 13374

95. Gueroussov S, Gonatopoulos-Pournatzis T, Irimia $M$, Raj B, Lin Z-Y, Gingras A-C, et al. An alternative splicing event amplifies evolutionary differences between vertebrates. Science (2015) 349:868-73. doi: 10.1126/science.aaa 8381

96. Jiang J, Chen X, Liu H, Shao J, Xie R, Gu P, et al. Polypyrimidine TractBinding Protein 1 promotes proliferation, migration and invasion in clearcell renal cell carcinoma by regulating alternative splicing of PKM. Am J Cancer Res. (2017) 7:245-59.

97. Schofield CJ, Ratcliffe PJ. Oxygen sensing by HIF hydroxylases. Nat Rev Mol Cell Biol. (2004) 5:343-54. doi: 10.1038/nrm1366

98. Loenarz C, Schofield CJ. Physiological and biochemical aspects of hydroxylations and demethylations catalyzed by human 2oxoglutarate oxygenases. Trends Biochem Sci. (2011) 36:7-18. doi: 10.1016/j.tibs.2010.07.002

99. Markolovic S, Wilkins SE, Schofield CJ. Protein Hydroxylation Catalyzed by 2-Oxoglutarate-dependent Oxygenases. J Biol Chem. (2015) 290:20712-22. doi: $10.1074 /$ jbc.R115.662627

100. Salminen A, Kauppinen A, Kaarniranta K. 2-Oxoglutarate-dependent dioxygenases are sensors of energy metabolism, oxygen availability, and iron homeostasis: potential role in the regulation of aging process. Cell Mol Life Sci. (2015) 72:3897-914. doi: 10.1007/s00018-0151978-z

101. Sullivan LB, Gui DY, Heiden MGV. Altered metabolite levels in cancer: implications for tumour biology and cancer therapy. Nat Rev Cancer (2016) 16:680-93. doi: 10.1038/nrc.2016.85

102. Frezza C, Pollard PJ, Gottlieb E. Inborn and acquired metabolic defects in cancer. J Mol Med. (2011) 89:213-20. doi: 10.1007/s00109-011-0728-4

103. Ward PS, Patel J, Wise DR, Abdel-Wahab O, Bennett BD, Coller $\mathrm{HA}$, et al. The common feature of leukemia-associated IDH1 and IDH2 mutations is a neomorphic enzyme activity converting alphaketoglutarate to 2-hydroxyglutarate. Cancer Cell (2010) 17:225-34. doi: 10.1016/j.ccr.2010.01.020

104. Figueroa ME, Abdel-Wahab O, Lu C, Ward PS, Patel J, Shih A, et al. Leukemic IDH1 and IDH2 mutations result in a hypermethylation phenotype, disrupt TET2 function, and impair hematopoietic differentiation. Cancer Cell (2010) 18:553-67. doi: 10.1016/j.ccr.2010.11.015 
105. Flavahan WA, Drier Y, Liau BB, Gillespie SM, Venteicher AS, StemmerRachamimov $\mathrm{AO}$, et al. Insulator dysfunction and oncogene activation in IDH mutant gliomas. Nature (2016) 529:110-4. doi: 10.1038/nature16490

106. Adam J, Yang M, Bauerschmidt C, Kitagawa M, O’Flaherty L, Maheswaran $\mathrm{P}$, et al. A role for cytosolic fumarate hydratase in urea cycle metabolism and renal neoplasia. Cell Rep. (2013) 3:1440-8. doi: 10.1016/j.celrep.2013.04.006

107. Letouzé E, Martinelli C, Loriot C, Burnichon N, Abermil N, Ottolenghi $\mathrm{C}$, et al. SDH mutations establish a hypermethylator phenotype in paraganglioma. Cancer Cell (2013) 23:739-52. doi: 10.1016/j.ccr.2013.04.018

108. Xiao M, Yang H, Xu W, Ma S, Lin H, Zhu H, et al. Inhibition of $\alpha-K G-$ dependent histone and DNA demethylases by fumarate and succinate that are accumulated in mutations of FH and SDH tumor suppressors. Genes Dev. (2012) 26:1326-38. doi: 10.1101/gad.191056.112

109. Laukka T, Mariani CJ, Ihantola T, Cao JZ, Hokkanen J, Kaelin WG, et al. Fumarate and Succinate Regulate Expression of Hypoxiainducible Genes via TET Enzymes. J Biol Chem. (2016) 291:4256-65. doi: 10.1074/jbc.M115.688762

110. Wentzel JF, Lewies A, Bronkhorst AJ, van Dyk E, Plessis du LH, Pretorius PJ. Exposure to high levels of fumarate and succinate leads to apoptotic cytotoxicity and altered global DNA methylation profiles in vitro. Biochimie (2017) 135:28-34. doi: 10.1016/j.biochi.2017.01.004

111. Salminen A, Kaarniranta K, Hiltunen M, Kauppinen A. Krebs cycle dysfunction shapes epigenetic landscape of chromatin: novel insights into mitochondrial regulation of aging process. Cell Signal. (2014) 26:1598-603. doi: 10.1016/j.cellsig.2014.03.030

112. Wise DR, DeBerardinis RJ, Mancuso A, Sayed N, Zhang X-Y, Pfeiffer HK, et al. Myc regulates a transcriptional program that stimulates mitochondrial glutaminolysis and leads to glutamine addiction. Proc Natl Acad Sci USA. (2008) 105:18782-787. doi: 10.1073/pnas.0810199105

113. Stine ZE, Walton ZE, Altman BJ, Hsieh AL, Dang CV. MYC, Metabolism, and Cancer. Cancer Discov. (2015) 5:1024-39. doi: 10.1158/2159-8290.CD-15-0507

114. Coller HA, Grandori C, Tamayo P, Colbert T, Lander ES, Eisenman RN, et al. Expression analysis with oligonucleotide microarrays reveals that MYC regulates genes involved in growth, cell cycle, signaling, and adhesion. Proc Natl Acad Sci USA. (2000) 97:3260-5.

115. Sciacovelli M, Guzzo G, Morello V, Frezza C, Zheng L, Nannini N, et al. The mitochondrial chaperone TRAP1 promotes neoplastic growth by inhibiting succinate dehydrogenase. Cell Metab. (2013) 17:988-99. doi: 10.1016/j.cmet.2013.04.019

116. Roach PL, Clifton IJ, Fülöp V, Harlos K, Barton GJ, Hajdu J, et al. Crystal structure of isopenicillin $\mathrm{N}$ synthase is the first from a new structural family of enzymes. Nature (1995) 375:700-4. doi: 10.1038/375700a0

117. McDonough MA, Loenarz C, Chowdhury R, Clifton IJ, Schofield CJ. Structural studies on human 2-oxoglutarate dependent oxygenases. Curr Opin Struct Biol. (2010) 20:659-72. doi: 10.1016/j.sbi.2010.08.006

118. Markolovic S, Leissing TM, Chowdhury R, Wilkins SE, Lu X, Schofield CJ. Structure-function relationships of human JmjC oxygenasesdemethylases versus hydroxylases. Curr Opin Struct Biol. (2016) 41:62-72. doi: 10.1016/j.sbi.2016.05.013

119. Wu H, Zhang Y. Reversing DNA methylation: mechanisms, genomics, and biological functions. Cell (2014) 156:45-68. doi: 10.1016/j.cell.2013.12.019

120. Cao G, Li H-B, Yin Z, Flavell RA. Recent advances in dynamic m6A RNA modification. Open Biol. (2016) 6:160003. doi: 10.1098/rsob.160003

121. Kooistra SM, Helin K. Molecular mechanisms and potential functions of histone demethylases. Nat Rev Mol Cell Biol. (2012) 13:297-311. doi: $10.1038 / \mathrm{nrm} 3327$

122. Hancock RL, Dunne K, Walport LJ, Flashman E, Kawamura A. Epigenetic regulation by histone demethylases in hypoxia. Epigenomics (2015) 7:791811. doi: $10.2217 /$ epi.15.24

123. Williams ST, Walport LJ, Hopkinson RJ, Madden SK, Chowdhury R, Schofield CJ, et al. Studies on the catalytic domains of multiple JmjC oxygenases using peptide substrates. Epigenetics (2014) 9:1596-603. doi: 10.4161/15592294.2014.983381

124. Cascella B, Mirica LM. Kinetic analysis of iron-dependent histone demethylases: $\alpha$-ketoglutarate substrate inhibition and potential relevance to the regulation of histone demethylation in cancer cells. Biochemistry (2012) 51:8699-701. doi: 10.1021/bi3012466
125. Pollard PJ, Loenarz C, Mole DR, McDonough MA, Gleadle JM, Schofield CJ, et al. Regulation of Jumonji-domain-containing histone demethylases by hypoxia-inducible factor (HIF)-1alpha. Biochem J. (2008) 416:387-94. doi: 10.1042/BJ20081238

126. Gonzalez I, Munita R, Agirre E, Dittmer TA, Gysling K, Misteli T, et al. A lncRNA regulates alternative splicing via establishment of a splicing-specific chromatin signature. Nat Struct Mol Biol. (2015) 22:370-6. doi: $10.1038 / \mathrm{nsmb} .3005$

127. Zoabi M, Nadar-Ponniah PT, Khoury-Haddad H, Usaj M, Budowski-Tal I, Haran T, Henn A, et al. RNA-dependent chromatin localization of KDM4D lysine demethylase promotes H3K9me3 demethylation. Nucleic Acids Res. (2014) 42:13026-38. doi: 10.1093/nar/gku1021

128. He R, Kidder BL. H3K4 demethylase KDM5B regulates global dynamics of transcription elongation and alternative splicing in embryonic stem cells. Nucleic Acids Res. (2017) 45:6427-41. doi: 10.1093/nar/gkx251

129. Khan DH, Gonzalez C, Tailor N, Hamedani MK, Leygue E, Davie JR. Dynamic histone acetylation of $\mathrm{H} 3 \mathrm{~K} 4 \mathrm{me} 3$ nucleosome regulates MCL1 Pre-mRNA splicing. J Cell Physiol. (2016) 231:2196-204. doi: 10.1002/jcp. 25337

130. Cikala M, Alexandrova O, David CN, Pröschel M, Stiening B, Cramer P, et al. The phosphatidylserine receptor from Hydra is a nuclear protein with potential Fe(II) dependent oxygenase activity. BMC Cell Biol. (2004) 5:26. doi: 10.1186/1471-2121-5-26

131. Poulard C, Rambaud J, Lavergne E, Jacquemetton J, Renoir J-M, Trédan O, et al. Role of JMJD6 in Breast Tumourigenesis. PLoS ONE (2015) 10:e0126181. doi: 10.1371/journal.pone.0126181

132. Wang F, He L, Huangyang P, Liang J, Si W, Yan R, et al. JMJD6 promotes colon carcinogenesis through negative regulation of $\mathrm{p} 53$ by hydroxylation. PLoS Biol. (2014) 12:e1001819. doi: 10.1371/journal.pbio.1001819

133. Wan J, Xu W, Zhan J, Ma J, Li X, Xie Y, et al. PCAF-mediated acetylation of transcriptional factor HOXB9 suppresses lung adenocarcinoma progression by targeting oncogenic protein JMJD6. Nucleic Acids Res. (2016) 44:10662-75. doi: 10.1093/nar/gkw808

134. Lee C-R, Lee SH, Rigas NK, Kim RH, Kang MK, Park N-H, et al. Elevated expression of JMJD6 is associated with oral carcinogenesis and maintains cancer stemness properties. Carcinogenesis (2016) 37:119-28. doi: 10.1093/carcin/bgv169

135. Aprelikova O, Chen K, Touny El LH, Brignatz-Guittard C, Han J, Qiu T, et al. The epigenetic modifier JMJD6 is amplified in mammary tumors and cooperates with c-Myc to enhance cellular transformation, tumor progression, and metastasis. Clin Epigenetics (2016) 8:38. doi: 10.1186/s13148-016-0205-6

136. Chang B, Chen Y, Zhao Y, Bruick RK. JMJD6 is a histone arginine demethylase. Science (2007) 318:444-7. doi: 10.1126/science.1145801

137. Webby CJ, Wolf A, Gromak N, Dreger M, Kramer H, Kessler B, et al. Jmjd6 catalyses lysyl-hydroxylation of U2AF65, a protein associated with RNA splicing. Science (2009) 325:90-3. doi: 10.1126/science. 1175865

138. Yi J, Shen H-F, Qiu J-S, Huang M-F, Zhang W-J, Ding J-C, et al. JMJD6 and U2AF65 co-regulate alternative splicing in both JMJD6 enzymatic activity dependent and independent manner. Nucleic Acids Res. (2017) 45:3503-18. doi: 10.1093/nar/gkw1144

139. Wolf A, Mantri M, Heim A, Müller U, Fichter E, Mackeen MM, et al. The polyserine domain of the lysyl-5 hydroxylase Jmjd6 mediates subnuclear localization. Biochem J. (2013) 453:357-70. doi: 10.1042/BJ20130529

140. Hong X, Zang J, White J, Wang C, Pan C-H, Zhao R, et al. Interaction of JMJD6 with single-stranded RNA. Proc Natl Acad Sci USA. (2010) 107:14568-72. doi: 10.1073/pnas.1008832107

141. Heim A, Grimm C, Müller U, Häußler S, Mackeen MM, Merl J, et al. Jumonji domain containing protein 6 (Jmjd6) modulates splicing and specifically interacts with arginine-serine-rich (RS) domains of SR- and SR-like proteins. Nucleic Acids Res. (2014) 42:7833-50. doi: 10.1093/nar/gku488

142. Filarsky M, Zillner K, Araya I, Villar-Garea A, Merkl R, Längst G, et al The extended AT-hook is a novel RNA binding motif. RNA Biol. (2015) 12:864-76. doi: 10.1080/15476286.2015.1060394

143. Liu W, Ma Q, Wong K, Li W, Ohgi K, Zhang J, et al. Brd4 and JMJD6associated anti-pause enhancers in regulation of transcriptional pause release. Cell (2013) 155:1581-95. doi: 10.1016/j.cell.2013.10.056 
144. Hussong M, Kaehler C, Kerick M, Grimm C, Franz A, Timmermann B, et al. The bromodomain protein BRD4 regulates splicing during heat shock. Nucleic Acids Res. (2017) 45:382-94. doi: 10.1093/nar/gkw729

145. Barboric M, Lenasi T, Chen H, Johansen EB, Guo S, Peterlin BM. 7SK snRNP/P-TEFb couples transcription elongation with alternative splicing and is essential for vertebrate development. Proc Natl Acad Sci USA. (2009) 106:7798-803. doi: 10.1073/pnas.0903188106

146. Ji X, Zhou Y, Pandit S, Huang J, Li H, Lin CY, et al. SR proteins collaborate with 7SK and promoter-associated nascent RNA to release paused polymerase. Cell (2013) 153:855-68. doi: 10.1016/j.cell.2013.04.028

147. Rahman S, Sowa ME, Ottinger M, Smith JA, Shi Y, Harper JW, et al. The Brd4 extraterminal domain confers transcription activation independent of pTEFb by recruiting multiple proteins, including NSD3. Mol Cell Biol. (2011) 31:2641-52. doi: 10.1128/MCB.01341-10

148. Tsai W-C, Reineke LC, Jain A, Jung SY, Lloyd RE. Histone arginine demethylase JMJD6 is linked to stress granule assembly through demethylation of the stress granule-nucleating protein G3BP1. J Biol Chem. (2017) 292:18886-96. doi: 10.1074/jbc.M117.800706

149. Boeckel J-N, Guarani V, Koyanagi M, Roexe T, Lengeling A, Schermuly RT, et al. Jumonji domain-containing protein 6 (Jmjd6) is required for angiogenic sprouting and regulates splicing of VEGF-receptor 1. Proc Natl Acad Sci USA. (2011) 108:3276-81. doi: 10.1073/pnas.1008098108

150. Palmer KR, Tong S, Tuohey L, Cannon P, Ye L, Hannan NJ, et al. Jumonji domain containing protein 6 is decreased in human preeclamptic placentas and regulates sFLT-1 splice variant production. Biol Reprod. (2016) 94:59. doi: 10.1095/biolreprod.115.134460

151. Hu Y-J, Belaghzal H, Hsiao W-Y, Qi J, Bradner JE, Guertin DA, et al. Transcriptional and post-transcriptional control of adipocyte differentiation by Jumonji domain-containing protein 6. Nucleic Acids Res. (2015) 43:7790-804. doi: 10.1093/nar/gkv645

152. Liu X, Si W, Liu X, He L, Ren J, Yang Z, et al. JMJD6 promotes melanoma carcinogenesis through regulation of the alternative splicing of PAK1, a key MAPK signaling component. Mol Cancer (2017) 16:175. doi: 10.1186/s12943-017-0744-2

153. He Y-F, Li B-Z, Li Z, Liu P, Wang Y, Tang Q, et al. Tet-mediated formation of 5-carboxylcytosine and its excision by TDG in mammalian DNA. Science (2011) 333:1303-7. doi: 10.1126/science.1210944

154. Ito S, Shen L, Dai Q, Wu SC, Collins LB, Swenberg JA, et al. Tet proteins can convert 5-methylcytosine to 5-formylcytosine and 5-carboxylcytosine. Science (2011) 333:1300-3. doi: 10.1126/science.1210597

155. Kohli RM, Zhang Y. TET enzymes, TDG and the dynamics of DNA demethylation. Nature (2013) 502:472-9. doi: 10.1038/nature12750

156. Rasmussen KD, Helin K. Role of TET enzymes in DNA methylation, development, and cancer. Genes Dev. (2016) 30:733-50. doi: $10.1101 /$ gad.276568.115

157. Stroud H, Feng S, Morey Kinney S, Pradhan S, Jacobsen SE. 5Hydroxymethylcytosine is associated with enhancers and gene bodies in human embryonic stem cells. Genome Biol. (2011) 12:R54. doi: 10.1186/gb-2011-12-6-r54

158. Kim M, Park Y-K, Kang T-W, Lee S-H, Rhee Y-H, Park J-L, et al. Dynamic changes in DNA methylation and hydroxymethylation when hES cells undergo differentiation toward a neuronal lineage. Hum Mol Genet. (2014) 23:657-67. doi: 10.1093/hmg/ddt453

159. Wu H, D’Alessio AC, Ito S, Wang Z, Cui K, Zhao K, et al. Genome-wide analysis of 5-hydroxymethylcytosine distribution reveals its dual function in transcriptional regulation in mouse embryonic stem cells. Genes Dev. (2011) 25:679-84. doi: 10.1101/gad.2036011

160. Zheng Z, Ambigapathy G, Keifer J. MeCP2 regulates Tet1-catalyzed demethylation, CTCF binding, and learning-dependent alternative splicing of the BDNF gene in Turtle. Elife (2017) 6:525. doi: 10.7554/eLife.25384

161. Marina RJ, Sturgill D, Bailly MA, Thenoz M, Varma G, Prigge MF, et al. TET-catalyzed oxidation of intragenic 5-methylcytosine regulates CTCF-dependent alternative splicing. EMBO J. (2016) 35:335-55. doi: 10.15252/embj.201593235

162. Spruijt CG, Gnerlich F, Smits AH, Pfaffeneder T, Jansen PWTC, Bauer C, et al. Dynamic readers for 5-(hydroxy)methylcytosine and its oxidized derivatives. Cell (2013) 152:1146-59. doi: 10.1016/j.cell.2013.02.004
163. Wang L, Zhou Y, Xu L, Xiao R, Lu X, Chen L, et al. Molecular basis for 5-carboxycytosine recognition by RNA polymerase II elongation complex. Nature (2015) 523:621-5. doi: 10.1038/nature14482

164. Marina RJ, Oberdoerffer S. Epigenomics meets splicing through the TETs and CTCF. Cell Cycle (2016) 15:1397-9. doi: 10.1080/15384101.2016.1171650

165. Pastor WA, Aravind L, Rao A. TETonic shift: biological roles of TET proteins in DNA demethylation and transcription. Nat Rev Mol Cell Biol. (2013) 14:341-56. doi: 10.1038/nrm3589

166. Mason EF, Hornick JL. Succinate dehydrogenase deficiency is associated with decreased 5-hydroxymethylcytosine production in gastrointestinal stromal tumors: implications for mechanisms of tumorigenesis. Mod Pathol. (2013) 26:1492-7. doi: 10.1038/modpathol.2013.86

167. Abdel-Wahab O, Mullally A, Hedvat C, Garcia-Manero G, Patel J, Wadleigh $M$, et al. Genetic characterization of TET1, TET2, and TET3 alterations in myeloid malignancies. Blood (2009) 114:144-7. doi: 10.1182/blood-2009-03-210039

168. Langemeijer SMC, Kuiper RP, Berends M, Knops R, Aslanyan MG, Massop $\mathrm{M}$, et al. Acquired mutations in TET2 are common in myelodysplastic syndromes. Nat Genet. (2009) 41:838-42. doi: 10.1038/ng.391

169. Delhommeau F, Dupont S, Valle Della V, James C, Trannoy S, Massé A, et al. Mutation in TET2 in myeloid cancers. N Engl J Med. (2009) 360:2289-301. doi: 10.1056/NEJMoa0810069

170. Dolnik A, Engelmann JC, Scharfenberger-Schmeer M, Mauch J, KelkenbergSchade S, Haldemann B, et al. Commonly altered genomic regions in acute myeloid leukemia are enriched for somatic mutations involved in chromatin remodeling and splicing. Blood (2012) 120:e83-92. doi: 10.1182/blood-2011-12-401471

171. Jhanwar SC. Genetic and epigenetic pathways in myelodysplastic syndromes: a brief overview. Adv Biol Regul. (2015) 58:28-37. doi: 10.1016/j.jbior.2014.11.002

172. Haferlach T, Nagata Y, Grossmann V, Okuno Y, Bacher U, Nagae G, et al. Landscape of genetic lesions in 944 patients with myelodysplastic syndromes. Leukemia (2014) 28:241-7. doi: 10.1038/leu.2013.336

173. Zorzan E, Hanssens K, Giantin M, Dacasto M, Dubreuil P. Mutational Hotspot of TET2, IDH1, IDH2, SRSF2, SF3B1, KRAS, and NRAS from Human Systemic Mastocytosis Are Not Conserved in Canine Mast Cell Tumors. PLoS ONE (2015) 10:e0142450. doi: 10.1371/journal.pone.0142450

174. Hanssens K, Brenet F, Agopian J, Georgin-Lavialle S, Damaj G, Cabaret L, et al. SRSF2-p95 hotspot mutation is highly associated with advanced forms of mastocytosis and mutations in epigenetic regulator genes. Haematologica (2014) 99:830-5. doi: 10.3324/haematol.2013.095133

175. Adhikari S, Xiao W, Zhao Y-L, Yang Y-G. m(6)A: Signaling for mRNA splicing. RNA Biol. (2016) 13:756-9. doi: 10.1080/15476286.2016.1201628

176. Ke S, Alemu EA, Mertens C, Gantman EC, Fak JJ, Mele A, et al. A majority of m6A residues are in the last exons, allowing the potential for 3' UTR regulation. Genes Dev. (2015) 29:2037-53. doi: 10.1101/gad.269415.115

177. Liu J, Yue Y, Han D, Wang X, Fu Y, Zhang L, et al. A METTL3-METTL14 complex mediates mammalian nuclear RNA N6-adenosine methylation. Nat Chem Biol. (2014) 10:93-5. doi: 10.1038/nchembio.1432

178. Jia G, Fu Y, Zhao X, Dai Q, Zheng G, Yang Y, et al. N6-methyladenosine in nuclear RNA is a major substrate of the obesity-associated FTO. Nat Chem Biol. (2011) 7:885-7. doi: 10.1038/nchembio.687

179. Zheng G, Dahl JA, Niu Y, Fedorcsak P, Huang C-M, Li CJ, et al. ALKBH5 is a mammalian RNA demethylase that impacts RNA metabolism and mouse fertility. Mol Cell (2013) 49:18-29. doi: 10.1016/j.molcel.2012. 10.015

180. Fedeles BI, Singh V, Delaney JC, Li D, Essigmann JM. The AlkB Family of $\mathrm{Fe}(\mathrm{II}) / \alpha$-Ketoglutarate-dependent Dioxygenases: Repairing Nucleic Acid Alkylation Damage and Beyond. J Biol Chem. (2015) 290:20734-42. doi: 10.1074/jbc.R115.656462

181. Xu C, Wang X, Liu K, Roundtree IA, Tempel W, Li Y, et al. Structural basis for selective binding of m6A RNA by the YTHDC1 YTH domain. Nat Chem Biol. (2014) 10:927-9. doi: 10.1038/nchembio.1654

182. Alarcón CR, Goodarzi H, Lee H, Liu X, Tavazoie S, Tavazoie SF. HNRNPA2B1 Is a Mediator of m(6)A-Dependent Nuclear RNA Processing Events. Cell (2015) 162:1299-308. doi: 10.1016/j.cell.2015.08.011 
183. Xiao W, Adhikari S, Dahal U, Chen Y-S, Hao Y-J, Sun B$F$, et al. Nuclear m(6)A Reader YTHDC1 Regulates mRNA Splicing. Mol Cell (2016) 61:507-19. doi: 10.1016/j.molcel.2016. 01.012

184. Zhao X, Yang Y, Sun B-F, Shi Y, Yang X, Xiao W, et al. FTOdependent demethylation of N6-methyladenosine regulates mRNA splicing and is required for adipogenesis. Cell Res. (2014) 24:1403-19. doi: $10.1038 / \mathrm{cr} .2014 .151$

185. Bartosovic M, Molares HC, Gregorova P, Hrossova D, Kudla G, Vanacova S. N6-methyladenosine demethylase FTO targets pre-mRNAs and regulates alternative splicing and 3'-end processing. Nucleic Acids Res. (2017) 45:11356-70. doi: 10.1093/nar/gkx778

186. Tang C, Klukovich R, Peng H, Wang Z, Yu T, Zhang Y, et al. ALKBH5dependent m6A demethylation controls splicing and stability of long 3'-UTR mRNAs in male germ cells. Proc Natl Acad Sci USA. (2018) 115:E325-33. doi: $10.1073 /$ pnas. 1717794115

187. Fischer J, Koch L, Emmerling C, Vierkotten J, Peters T, Brüning JC, et al. Inactivation of the Fto gene protects from obesity. Nature (2009) 458:894-8. doi: $10.1038 /$ nature 07848

188. Ma M, Harding HP, O’Rahilly S, Ron D, Yeo GSH. Kinetic analysis of FTO (fat mass and obesity-associated) reveals that it is unlikely to function as a sensor for 2-oxoglutarate. Biochem J. (2012) 444:183-7. doi: 10.1042/BJ20120065

189. White E. Exploiting the bad eating habits of Ras-driven cancers. Genes Dev. (2013) 27:2065-71. doi: 10.1101/gad.228122.113

190. Pavlova NN, Thompson CB. The Emerging Hallmarks of Cancer Metabolism. Cell Metab. (2016) 23:27-47. doi: 10.1016/j.cmet.2015.12.006

191. Yang W, Zheng Y, Xia Y, Ji H, Chen X, Guo F, et al. ERK1/2dependent phosphorylation and nuclear translocation of PKM2 promotes the Warburg effect. Nat Cell Biol. (2012) 14:1295-304. doi: 10.1038/ ncb2629

192. Zhao Y, Butler EB, Tan M. Targeting cellular metabolism to improve cancer therapeutics. Cell Death Dis. (2013) 4:e532. doi: 10.1038/cddis. 2013.60

193. Koh CM, Sabò A, Guccione E. Targeting MYC in cancer therapy: RNA processing offers new opportunities. Bioessays (2016) 38:266-75. doi: 10.1002/bies.201500134

194. Hsu TY-T, Simon LM, Neill NJ, Marcotte R, Sayad A, Bland CS, et al. The spliceosome is a therapeutic vulnerability in MYC-driven cancer. Nature (2015) 525:384-8. doi: 10.1038/nature14985

195. Lee SC-W, Abdel-Wahab O. Therapeutic targeting of splicing in cancer. Nat Med. (2016) 22:976-86. doi: 10.1038/nm.4165

196. Calabretta S, Bielli P, Passacantilli I, Pilozzi E, Fendrich V, Capurso $\mathrm{G}$, et al. Modulation of PKM alternative splicing by PTBP1 promotes gemcitabine resistance in pancreatic cancer cells. Oncogene (2016) 35:20319. doi: $10.1038 /$ onc. 2015.270
197. Tummala R, Lou W, Gao AC, Nadiminty N. Quercetin targets hnRNPA1 to overcome enzalutamide resistance in prostate cancer cells. Mol Cancer Ther. (2017) 16:2770-9. doi: 10.1158/1535-7163.MCT-17-0030

198. Wang Z, Jeon HY, Rigo F, Bennett CF, Krainer AR. Manipulation of PK-M mutually exclusive alternative splicing by antisense oligonucleotides. Open Biol. (2012) 2:120133. doi: 10.1098/rsob.120133

199. Hua Y, Liu YH, Sahashi K, Rigo F, Bennett CF, Krainer AR. Motor neuron cell-nonautonomous rescue of spinal muscular atrophy phenotypes in mild and severe transgenic mouse models. Genes Dev. (2015) 29:288-97. doi: 10.1101/gad.256644.114

200. Finkel RS, Chiriboga CA, Vajsar J, Day JW, Montes J, De Vivo DC, et al. Treatment of infantile-onset spinal muscular atrophy with nusinersen: a phase 2, open-label, dose-escalation study. Lancet (2016) 388:3017-26. doi: 10.1016/S0140-6736(16)31408-8

201. Han J, Li J, Ho JC, Chia GS, Kato H, Jha S, et al. Hypoxia is a key driver of alternative splicing in human breast cancer cells. Sci Rep. (2017) 7:4108. doi: 10.1038/s41598-017-04333-0

202. Jakubauskiene E, Vilys L, Makino Y, Poellinger L, Kanopka A Increased Serine-Arginine (SR) Protein Phosphorylation Changes Pre-mRNA Splicing in Hypoxia. J Biol Chem. (2015) 290:18079-89. doi: 10.1074/jbc.M115.639690

203. Salton M, Misteli T. Small Molecule Modulators of Pre-mRNA Splicing in Cancer Therapy. Trends Mol Med. (2016) 22:28-37. doi: 10.1016/j.molmed.2015.11.005

204. Iwai K, Yaguchi M, Nishimura K, Yamamoto Y, Tamura T, Nakata D, et al. Anti-tumor efficacy of a novel CLK inhibitor via targeting RNA splicing and MYC-dependent vulnerability. EMBO Mol Med. (2018) 10:e8289. doi: 10.15252/emmm.201708289

205. Matsumoto K, Obara N, Ema M, Horie M, Naka A, Takahashi $\mathrm{S}$, et al. Antitumor effects of 2-oxoglutarate through inhibition of angiogenesis in a murine tumor model. Cancer Sci. (2009) 100:1639-47. doi: 10.1111/j.1349-7006.2009.01249.x

Conflict of Interest Statement: The authors declare that the research was conducted in the absence of any commercial or financial relationships that could be construed as a potential conflict of interest.

The reviewer TLS and handling Editor declared their shared affiliation.

Copyright (C) 2018 Biamonti, Maita and Montecucco. This is an open-access article distributed under the terms of the Creative Commons Attribution License (CC BY). The use, distribution or reproduction in other forums is permitted, provided the original author(s) and the copyright owner(s) are credited and that the original publication in this journal is cited, in accordance with accepted academic practice. No use, distribution or reproduction is permitted which does not comply with these terms. 